\title{
Assessment of LWR-HTR-GCFR Integrated Cycle
}

\author{
Eleonora Bomboni, ${ }^{1}$ Nicola Cerullo, ${ }^{1,2}$ and Guglielmo Lomonaco ${ }^{1}$ \\ ${ }^{1}$ DIMNP, University of Pisa, CIRTEN, Largo Lucio Lazzarino n. 2, 56126 Pisa, Italy \\ ${ }^{2}$ DIPTEM, University of Genova, Via all'Opera Pia 15/a, 16145 Genova, Italy
}

Correspondence should be addressed to Nicola Cerullo, cerullo@docenti.ing.unipi.it

Received 1 March 2009; Accepted 1 July 2009

Recommended by Jim Kuijper

Preliminary analyses already performed showed that innovative GCRs, both thermal and fast, are very promising candidate to reach the Gen-IV sustainability goal. The integrated LWR-HTR-GCFR basically aims at closing the current nuclear fuel cycle: in principle, thanks to the unique characteristics of Helium coolant reactors, LWR SNF along with DU become valuable material to produce energy. Additionally, burning HMs of LWR SNF means not only a drastic reduction in the $\mathrm{U}^{\text {nat }}$ demand but also a remarkable decrease in the long-term radiotoxic component of nuclear waste to be geologically stored. This paper focuses on the analyses of the LWR-HTR-GCFR cycle performed by the University of Pisa in the frame of the EU PUMA project (6th FP). Starting from a brief outline of the main characteristics of HTR and GCFR concepts and of the advantages of linking LWR, HTR and GCFR in a symbiotic way, this paper shows the integrated cycle involving a typical LWR (1000 MW $\left.\mathrm{M}_{\mathrm{e}}\right)$, a PBMR $\left(400 \mathrm{MW}_{\text {th }}\right)$ and a GCFR-"E" $\left(2400 \mathrm{MW}_{\text {th }}\right)$. Additionally, a brief overview of the main technological constraints concerning (Pu+MA)-based advanced fuels is given, in order to explain and justify the choices made in the framework of the considered cycle. Thereafter, calculations performed and results obtained are described.

Copyright (c) 2009 Eleonora Bomboni et al. This is an open access article distributed under the Creative Commons Attribution License, which permits unrestricted use, distribution, and reproduction in any medium, provided the original work is properly cited.

\section{Introduction}

Currently there are more than 440 power reactors running worldwide, supplying $16 \%$ of the total electricity produced. Nuclear power is, as known, the only $\mathrm{CO}_{2}$-free source that is capable to satisfy today's increasing energy demand. Nuclear power, thanks to the well-proven LWR technology, is very reliable and safe. Although among power plants Nuclear Power Plants (NPPs) have by far the highest ratio between energy supplied and waste produced, actually waste is their major drawback. Indeed, nuclear waste contains elements that are dangerous for more than 100000 years; additionally, the natural resources of nuclear fuel are badly exploited by the LWR technology, because of both neutronic and technological reasons. It has been being clear since the beginning of nuclear age that the nuclear fuel availability could be substantially increased by the FR technology, which is capable of utilizing almost $100 \%$ of $\mathrm{U}$ from mine against less than $1 \%$ of LWRs. Additionally, fissioning the whole $\mathrm{U}$ amount extracted from mine means to reduce the long-term radiotoxicity of the final waste as well. Thus, in order to reach these two goals contemporarily and to realize a "sustainable" nuclear power, more than one kind of reactors has to be used, linked each other in a "symbiotic" way. Although long and deep analyses are still requested, it is possible to draw a first assessment highlighting the potentialities of symbiotic cycles involving two of the most promising Generation IV reactor concepts: (V)HTR and GCFRs [17].

\section{The LWR Spent Nuclear Fuel}

As known, the discharge burnup of fuel elements depends on both nuclear and technological reasons, consequently it can be quite different for different kinds of reactor. Regarding LWR, the most widespread concept worldwide, it lies in the range between 30000 and $60000 \mathrm{MWd} / \mathrm{tHM}$. That entails that the mass loaded into a typical LWR (electric output equal to $1 \mathrm{GW}_{\mathrm{e}}$ and efficiency around $33 \%$ ) amounts to about 25/30 tons of HM per Full Power Year (FPY) and 
TABle 1: Spent LWR HM composition (burnup 33 GWD/tHM; initial enrichment $3.2 \% \mathrm{U}^{235}$; 5 years cooling).

\begin{tabular}{cccc}
\hline & Isotope & Quantity [g/t HM] & Mass fraction [\%] \\
& $\mathrm{Pu}^{238}$ & 140 & 1.5 \\
$\mathrm{Pu}$ & $\mathrm{Pu}^{239}$ & 5470 & 59.0 \\
& $\mathrm{Pu}^{240}$ & 2230 & 24.0 \\
& $\mathrm{Pu}^{241}$ & 956 & 10.3 \\
& $\mathrm{Pu}^{242}$ & 486 & 5.2 \\
\hline \multirow{4}{*}{$\mathrm{MA} \quad \mathrm{Np}^{237}$} & 437 & 51.6 \\
& $\mathrm{Am}^{241}$ & 296 & 35.0 \\
& $\mathrm{Am}^{243}$ & 83.8 & 9.9 \\
& $\mathrm{Cm}^{242}$ & 6.2 & 0.7 \\
& $\mathrm{Cm}^{244}$ & 24 & 2.8 \\
\hline
\end{tabular}

is followed by the same discharge rate of spent fuel, of which an important fraction is composed of TRansUranics (TRU).

After about 3 years of permanence inside the reactor core, the spent fuel is transferred to cooling pools. Approximately 350 different nuclides (200 of which radioactive) were created during irradiation, with the following average composition:

(i) $94 \% \mathrm{U}^{238}$,

(ii) $1 \% \mathrm{U}^{235}$ (hence, Spent Nuclear Fuel (SNF) is still enriched if compared to $U^{\text {nat }}$ ),

(iii) $1 \% \mathrm{Pu}$,

(iv) $0.1 \% \mathrm{MA}$,

(v) $3 \div 4 \%$ Fission Products (FP).

As far as the isotopic composition of $\mathrm{Pu}$ and MAs is concerned, it is shown in Table 1.

FP dangerousness decays in few centuries but $\mathrm{Pu}$ and MAs are very long-living, even more than 100000 years. Therefore, the management, the minimization of its quantity, and the safe disposal of the SNF are key issues for the present and the future of nuclear energy.

However, it is important to recognize that what is called "nuclear waste" is actually composed largely of recyclable material. In principle, all actinides are able to produce energy by fission, either directly or indirectly by transmutation into fissile nuclei by one or more neutronic captures. That means, $\sim 96 \%$ of SNF is potentially recyclable, whereas only FPs are "waste," at least from the energy production point of view (indeed, some of them could be extracted and used, as an example, for technological or medical applications) (as an exemple, some of them could be extracted and used for technological or medical applications).

At the moment, only $\mathrm{Pu}$ is partially recycled in Mixed Oxide (MOX) fuels for LWRs in some countries. MOX technology allows the possibility to double the current natural resource exploitation, which corresponds to less than $1 \%$ with the Once Through Then Out (OTTO) cycle. However, an integral use of $\mathrm{U}$ resources can be achieved

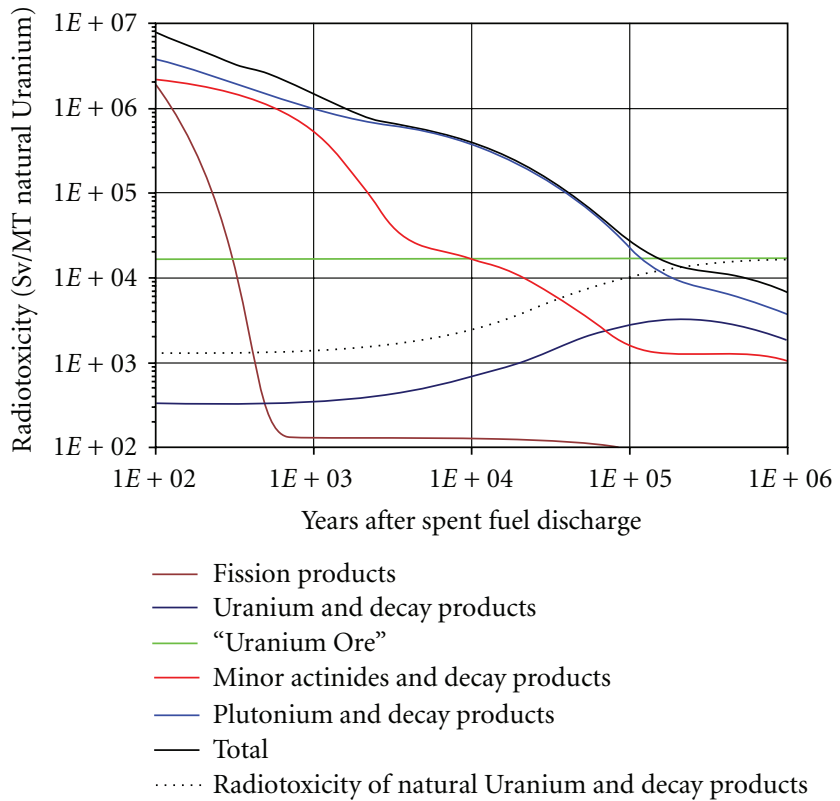

FIGURE 1: Radiotoxicity of SNF versus time.

only with the FR technology. Indeed, the Generation IV Initiative, aiming at a sustainable nuclear power, proposes 6 reactor concepts, among which 3 are fast: Sodium Fast Reactor (SFR), Lead Fast Reactor (LFR), along with the already mentioned GCFR. Additionally, recycling all HMs from SNF reduces the mass of the material to be stored in geological repositories and may also reduce its long-term radiotoxicity. This reduction will be very strong if the final waste is constituted of only FPs (see Figure 1): indeed, their radiotoxicity balances the reference level (the so-called Level Of Mine, LOM: the LOM corresponds to the radiotoxicity of that natural Uranium $\left(\mathrm{U}_{\text {nat }}\right)$ mass from which the considered waste descends) in less than 500 years.

Moreover, recycling HMs entails high neutronic fluencies on them and, consequently, the buildup of MAs and $\mathrm{Pu}$ nuclides with higher mass number (240 or more). That means, HMs are made useless for military purposes (it is useful to remember that at least $93 \%$ of $\mathrm{Pu}$-Weapons Grade $(\mathrm{Pu}-\mathrm{WG})$ is composed of $\mathrm{Pu}^{239}$, because $\mathrm{Pu}-\mathrm{WG}$ cannot contain more than $7 \%$ of $\mathrm{Pu}^{240}$ due to the relatively high self-fission probability of this latter isotope), because many of these heavier isotopes are characterized by both a high decay power and a high probability of self-fission (Table 2).

\section{Partitioning and Transmutation (P\&T) of Pu- and MA-based Advanced Fuels}

As partially anticipated in previous paragraphs, closing the nuclear fuel cycle (i.e., all HM from mine is exploited to produce energy by fission, directly or indirectly by transmutation, it is then reprocessed and recycled; the final nuclear waste consists of only FPs) would permit the possibility to solve almost all the open issues regarding nuclear power, while assuring the energy supply worldwide for the future 
TABLE 2: Decay power and other properties of some actinide nuclides [1].

\begin{tabular}{|c|c|c|c|c|c|}
\hline \multirow{2}{*}{ Nuclide } & \multirow{2}{*}{ Half-life (years) } & \multicolumn{3}{|c|}{ Specific activity } & \multirow{2}{*}{ Dose coefficients $\left(10^{-7} \mathrm{~Sv} / \mathrm{Bq}\right)$} \\
\hline & & $(\mathrm{Ci} / \mathrm{g})$ & $(\mathrm{W} / \mathrm{g})$ & (Neutron $\min ^{-1} \mathrm{mg}^{-1}$ ) & \\
\hline${ }^{237} \mathrm{NP}$ & $2.14 \times 10^{6}$ & $7.07 \times 10^{-4}$ & $2.07 \times 10^{-5}$ & $<7 \times 10^{-6}$ & 1.1 \\
\hline${ }^{238} \mathrm{PU}$ & 87.404 & 17.2 & 0.570 & 155 & 2.3 \\
\hline${ }^{239} \mathrm{PU}$ & $2.4413 \times 10^{4}$ & $6.13 \times 10^{-2}$ & $1.913 \times 10^{-3}$ & $1.35 \times 10^{-3}$ & 2.5 \\
\hline${ }^{240} \mathrm{PU}$ & 6580 & 0.227 & $7.097 \times 10^{-3}$ & 53.7 & 2.5 \\
\hline${ }^{241} \mathrm{PU}$ & 14.98 & 99.1 & $4.06 \times 10^{-3}$ & & 4.7 \\
\hline${ }^{242} \mathrm{PU}$ & $3.869 \times 10^{5}$ & $3.82 \times 10^{-3}$ & 1. $13 \times 10^{-4}$ & 95.3 & 2.4 \\
\hline${ }^{241} \mathrm{AM}$ & 432.7 & 3.43 & 0.1145 & $3.55 \times 10^{-2}$ & 2.0 \\
\hline${ }^{242 \mathrm{~m}} \mathrm{AM}$ & 144 & 10.3 & $3.08 \times 10^{-2}$ & & 1.9 \\
\hline${ }^{243} \mathrm{AM}$ & 7370 & 0.200 & $6.42 \times 10^{-3}$ & & 2.0 \\
\hline${ }^{242} \mathrm{CM}$ & 0.445 & $3.32 \times 10^{3}$ & 122 & $1.21 \times 10^{6}$ & 0.13 \\
\hline${ }^{244} \mathrm{CM}$ & 18.099 & 80.94 & 2.832 & $6.87 \times 10^{5}$ & 1.6 \\
\hline${ }^{243} \mathrm{CM}$ & 8265 & 0.177 & $5.89 \times 10^{-3}$ & & 3.0 \\
\hline${ }^{252} \mathrm{CF}$ & 2.64 & 537 & 38.3 & $2.3 \times 10^{12}$ & 0.98 \\
\hline
\end{tabular}

centuries. Of course, there are some challenging aspects at the moment as far as Partitioning and Transmutation (P\&T) are concerned. Probably, the best way to close the nuclear fuel cycle would be an integral fuel cycle (as proposed for GCFR reactors). In such an approach, the reprocessed spent fuel from LWRs is part of the feed for FRs. Then, the spent fuel of FRs is reprocessed in situ, and all HMs are recovered together (i.e., without chemical separation of the different elements) and reused to produce new fuel for the same FR fleet (multiple homogeneous recycle), while FPs constitutes the final waste. Such a strategy is at the moment quite challenging, because an economically feasible process is needed, allowing the possibility to treat highly radioactive materials and to extract HMs with a very high efficiency (more than 99\%). What is more, treating not-negligible quantities of MAs (particularly $\mathrm{Cm}$, due to its strong $\gamma$ and neutron emissions) seems to be quite difficult due to radioprotection problems, particularly in large facilities along with large amounts of all the other HMs. Additionally, all the processes involved should be very effective as far as the separation of HMs from FPs and the recoverability of reactants are concerned. Hence, at the moment it seems to be simpler recycling $\mathrm{U}, \mathrm{Pu}, \mathrm{Np}$, and, if appropriate, Am. Indeed, $\mathrm{Np}$ can be partitioned during the PUREX process, although this procedure has not yet been developed on an industrial scale. Regarding $\mathrm{Cm}$, it seems to be advisable to store it temporarily, while waiting for its decay into $\mathrm{Pu}$ (half-life of $\mathrm{Cm}^{244}$ is around 18 years), it is also quite challenging to separate it from Am due to their similar chemical behavior. Then, storing $\mathrm{Cm}$ could entail to store Am together as well. On the other hand, Am and $\mathrm{Cm}$ could be recovered in some smaller dedicated facilities and reused in dedicated assemblies (heterogeneous recycle) for critical reactors or for Accelerator Driven Systems (ADs). In this connection it is important to take into account that the following hold. (i) Recycling $\mathrm{Cm}$ entails the production of notnegligible quantities of $\mathrm{Cf}^{252}$, which is a very strong neutrons emitter (much stronger than $\mathrm{Cm}$ itself, Table 2) and, consequently, it is very difficult to be managed.

(ii) The opportunity of recycling Am without $\mathrm{Cm}$ has to be deeply assessed: indeed, it does not reduce the long-term radiotoxicity very much (not more than a factor $10 \mathrm{o}$ less, due to the production of $\mathrm{Cm}$ by neutron capture). That means a challenging procedure of partitioning could eventually not be very effective from the long-term radiotoxicity reduction point of view.

(iii) In principle, building dedicated facilities for Am and $\mathrm{Cm}$ recycling could not be economical.

As far as transmutation is concerned, a single reactor concept is probably not enough to burn HMs effectively, but this purpose can be reached by chains of different reactors, each doing what the others are not able to do. LWRs can be considered the starting point of all the possible chains, due to their current large diffusion worldwide, their proven technology and reliability, as well as, last but not least, the large amounts of LWR SNF worldwide. Additionally, as shown above, LWR SNF is rich in fissionable elements. Nevertheless, it is not possible to burn HMs completely in LWRs because of neutronic and technological reasons. Instead, FRs can exploit Pu by breeding $\mathrm{U}^{238}$, thus increasing largely the availability of nuclear fuel. Additionally, the good neutron economy of the fast spectrum enables us to transmute even $\mathrm{Pu}$ isotopes and MAs as well. Of course, thorough analyses are requested in order to use these new fuels, particularly concerning the dynamic behavior of the core. Indeed, the introduction of large fractions of $\mathrm{Pu}$ and MAs tends to make worse safety parameters like the Fuel Temperature Coefficient (FTC) and the effective delayed 
neutrons fraction $\left(\beta_{\text {eff }}\right)$. In this connection it is clear that cores with a high neutron economy are advisable, since they are able to reach and maintain the criticality with small fractions of $\mathrm{Pu}$.

On the basis of the considerations outlined until now, a fuel cycle is proposed in the following paragraphs that involves current LWRs, (V)HTRs, and GCFRs in a "symbiotic" way in order to exploit nuclear waste $(\mathrm{Pu}, \mathrm{Np}$, and Depleted Uranium from reprocessing plants if necessary) as fresh fuel.

\section{Computer Codes and Libraries}

MCNP [8] is a general purpose 3D MC code that can be used for neutron, photon, electron, and coupled neutron/photon/electron transport, including the capability to calculate the eigenvalues for critical systems. The current version has new interesting features, among which the capability to treat stochastic geometries like that characterizing HTR cores. As a general neutronic code, MCNP is able to calculate fluxes, one- or multigroup cross sections and other parameters typical of nuclear systems.

ORIGEN [9] is a deterministic depletion code based on the matrix exponential method. ORIGEN needs initial quantities of each material in the system, one-group crosssections, total power, and irradiation time of the system being analysed to calculate its burnup. If necessary, the user can supply feed and/or removal rate of each material to be burnt.

Monteburns [10] is a code coupling MCNP with a depletion code in order to perform burnup calculations. It consists of a Perl [11] script interacting with FORTRN77 program (monteb.f). Particularly, Monteburns2.0 requires Active PERL 5.6.1 build 635 for Windows. The current version 2.0 is able to use MCNP-4C, MCNP5, or MCNPX2.5 [12] with ORIGEN2.2 or CINDER90 [13]. The flowchart in Figure 2 shows how Monteburns works.

The primary way in which MCNP and ORIGEN interact through MONTEBURNS is that MCNP provides one-group microscopic cross-sections and fluxes to ORIGEN for burnup calculations. After ORIGEN and MCNP have been run, results for each burn step are written into output files, and the isotopic compositions obtained from ORIGEN are used to generate a new MCNP input file for the next burn step. This MCNP input file contains the adjusted composition and density of each material being analysed. To increase the accuracy of the burnup calculation, a "predictor" step is used in which ORIGEN is run halfway through the designated burn step. One-group cross-sections are then calculated at the midpoint of the burn step by MCNP. This assumes that the nuclides of the system at the midpoint are a reasonable approximation of the nuclides over the entire burn step (actually it is important only that the neutron flux energy spectrum be representative of the entire burn step). The user must be aware of this assumption and consequently ensure that burn intervals are not too long. After the predictor step is executed, then ORIGEN is re-executed with the new onegroup cross-sections.
Monteburns supplies, as output data, the following:

(i) $\mathrm{K}_{\text {eff versus time, }}$

(ii) recoverable energy per fission versus. time,

(iii) neutron flux versus time,

(iv) macroscopic fission cross section per material versus time,

(v) power generation versus time,

(vi) burnup versus time ( $\mathrm{GWd} /$ ton of heavy metal),

(vii) $(\mathrm{n}, \gamma),(\mathrm{n}, \mathrm{f})(\mathrm{n}, 2 \mathrm{n})$ microscopic XS per material versus time,

(viii) flux spectrum versus time,

(ix) grams of material versus time,

(x) activity of material versus time,

(xi) inhalation and ingestion radiotoxicity versus time.

As mentioned previously, we used MCNP5 and ORIGEN2.2 for the burnup calculation performed here.

In order to obtain the best reliability, we used the most recent cross-section libraries we have at the moment. Consequently, we chose the JEFF3.1 libraries for MCNP code. Anyway, for cross-sections not provided by MCNP, ORIGEN uses values from its own library. ORIGEN libraries are supplied as one-group tables of data, each of which is somewhat representative of a given type of reactor. They are substantially based on ENDF/B-IV nuclear data. Unfortunately, there is no library relevant to HTR of GCFR systems and consequently we used the generic THERMAL.LIB file for calculations on PBMR-400, and the FFTC.LIB file (library developed to simulate fast reactor spectra) for the GCFR core.

Regarding the FP yield model, we adopted the ORIGEN one [9].

\section{The PBMR-400 and the GCFR "E" Cores: Main Characteristics and Computational Models}

This work has been performed focusing on the PBMR-400 as a reference HTR pebble-bed core concept [1], and on the GCFR “E” 2400 as a GCFR core (plate type) concept [1].

PBMR is a pebble-bed, 400 MWth HTR core. It is an $11 \mathrm{~m}$ high annular core, with a central column of graphite as a reflector. Its refuelling scheme is a continuous one. The fuel elements are $6 \mathrm{~cm}$ diameter pebbles filled by TRISO-coated particles. In the frame of the PUMA EU project [2], kernels are composed of $\mathrm{Pu}$-oxide without any fertile elements ( $\mathrm{U}$ or Th). In the current analysis, PBMR kernels are composed of 1st generation $\mathrm{Pu}+\mathrm{Np}$-oxide. That means $\mathrm{Pu}$ and $\mathrm{Np}$ coming from an LWR are recovered as fresh fuel for the PBMR, whereas Am, Cm, and FPs are stored as waste.

GCFR " $E$ " is a 2400 MWth He-cooled fast reactor. Its fuel assemblies are hexagonal, containing plates made of a (U,Pu)C and SiC matrix. Thanks to its core composition with an extremely low content of parasitic absorbers, GCFR is able to reach criticality with a fuel composed of $82 \%$ (as an atomic 


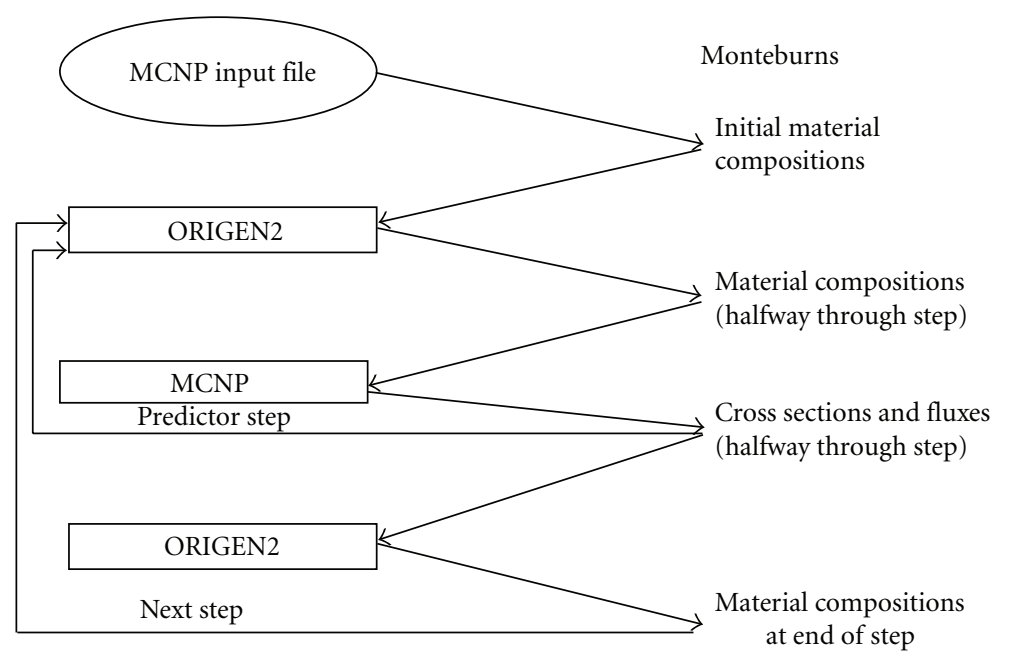

FIGURE 2: Monteburns workflow.

fraction) Depleted Uranium (DU), as well as to sustain very long irradiation period without becoming subcritical. Since for this core concept 10\% FIMA burnup is envisaged, we analysed GCFR multiple cycles that are more than 3100 days long. What is more, multiple recycles of the GCFR SNF have been analysed: the SNF of a cycle is recovered and reused as a fresh fuel for the following cycle. Am, Cm, and FPs are substituted by DU in order to keep constant the core fuel inventory.

Describing in detail PBMR and GCFR is a very challenging matter, not only for the huge computational time requested, but also for the lack of some data. Then, the main approximations we introduced to perform calculations are the following.

PBMR model.

(i) Pebbles are regularly arranged inside the core (BCC or CHPOP lattices have been both analysed and compared); as a comparison, calculations have been performed on a infinite lattice of pebbles as well.

(ii) Pebbles are fixed inside the core, that is, each pebble occupies the same position from BOC to EOC. Of course, such an approximation is a very rough one, but it may be considered a first step to refine the model with which a pebble-bed core is usually described in MC simulations (a single pebble with white boundary conditions).

(iii) Control rods have been considered fully extracted during the whole life.

(iv) The core has been supposed as symmetric and only one twelfth of the core has been modelled.

(v) Radial and axial core temperature profiles have not been taken into account, due to the code limitations; in order to roughly assess the effect of such an approximation, a comparison has been performed with a model divided into two axial zones as described in [1].

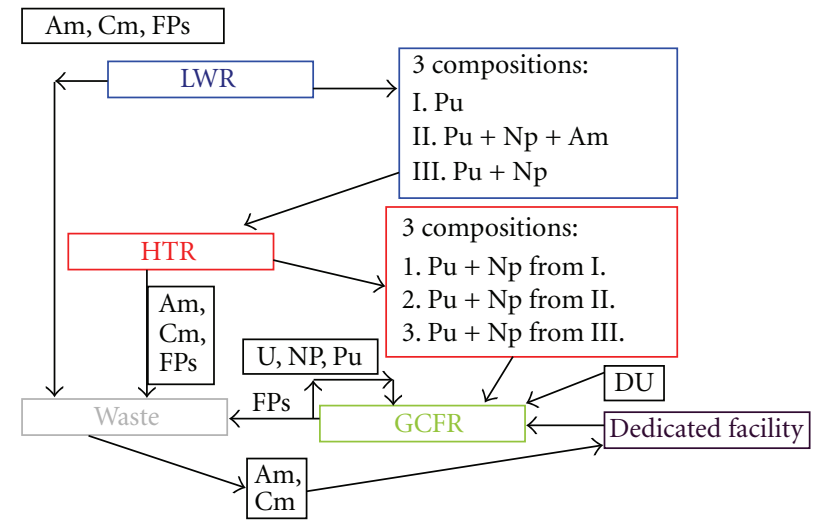

FIgURE 3: Sketch of the proposed cycle.

(vi) The ratio of the HM to the graphite mass is around 0.01 .

\section{GCFR model.}

(i) As for the PBMR model, radial and axial core temperature profiles have not been taken into account, due to the code limitations; in order to roughly assess the effect of such an approximation, a comparison has been performed with a model with two axial zones.

(ii) Control rods have not been modelled.

(iii) No refuelling scheme has been considered (single batch).

\section{Calculations and Results}

A sketch of the proposed cycle is shown in Figure 3.

The initial Heavy Metal composition of the PBMR fuel is shown in Table 3.

The PBMR core has been irradiated as a single-batch: that is, of course, not realistic, but it is due to the current code limitations. All the core models considered resulted to 
TABLE 3: PBMR initial HM composition (coming from typical LWR SNF; please see Table 1).

\begin{tabular}{ccccccc}
\hline & $\mathrm{Np}^{237}$ & $\mathrm{Pu}^{238}$ & $\mathrm{Pu}^{239}$ & $\mathrm{Pu}^{240}$ & $\mathrm{Pu}^{241}$ & $\mathrm{Pu}^{242}$ \\
\hline Mass fraction [\%] & 7.09 & 3.02 & 51.58 & 23.98 & 9.19 & 5.11 \\
\hline
\end{tabular}

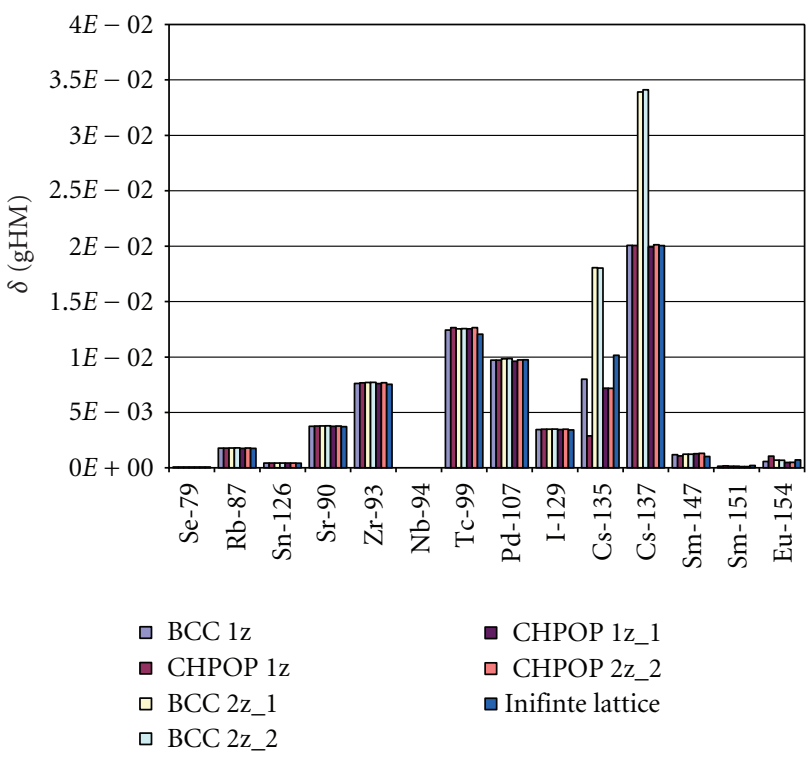

Figure 4: Production (grams) of some FPs per initial HM mass in the different PBMR core models (after 1063 EFPD).

maintain criticality up to about 800 Effective Full Power Days (EFPD).

Figures 4, 5, and 6 show the results we obtained as far as the fuel isotopic composition is concerned (BCC $1 \mathrm{z}$ is the Body Cubic Centered (BCC), 1-zone model; BCC $2 z_{-} 1$ is the BCC, 2-zone (axially) model, of which the composition of the upper (1) zone is considered; CHPOP $1 \mathrm{z}$ is the Column Hexagonal Point On Point (CHPOP), 1-zone model; etc.). We evaluated these compositions after 1062.50 EFPD, corresponding to about $530 \mathrm{GWd} / \mathrm{tHM}$, in order to assess the difference arising with the different models in case of very high burnup.

Conversely, as an isotopic vector of $\mathrm{Pu}$ and $\mathrm{Np}$ to be inserted into the GCFR fuel, the PBMR fuel after 712.50 EFPD (about $356 \mathrm{GWd} / \mathrm{tHM}$ ) has been considered. That is the burnup at which all the considered models are still critical. Of course, in this way we consider the worst case as far as the waste to energy ratio is concerned, obtaining a sort of upper limit for this parameter.

It is interesting to note that the considered core model does not strongly affect the fuel isotopic evolution, excepted for its $\mathrm{Cs}, \mathrm{Am}^{243}$, and $\mathrm{Cm}^{244}$ content. For these nuclides, the influence of the pebble arrangement (infinite lattice or BCC versus CHPOP) is more strong than the influence of the temperature profile (infinite lattice or 1-zone versus 2zones). That is an interesting result, since it demonstrates that rough models like the infinite lattice work reasonably well at least for survey calculations, as far as the prediction of the fuel isotopic evolution is concerned.

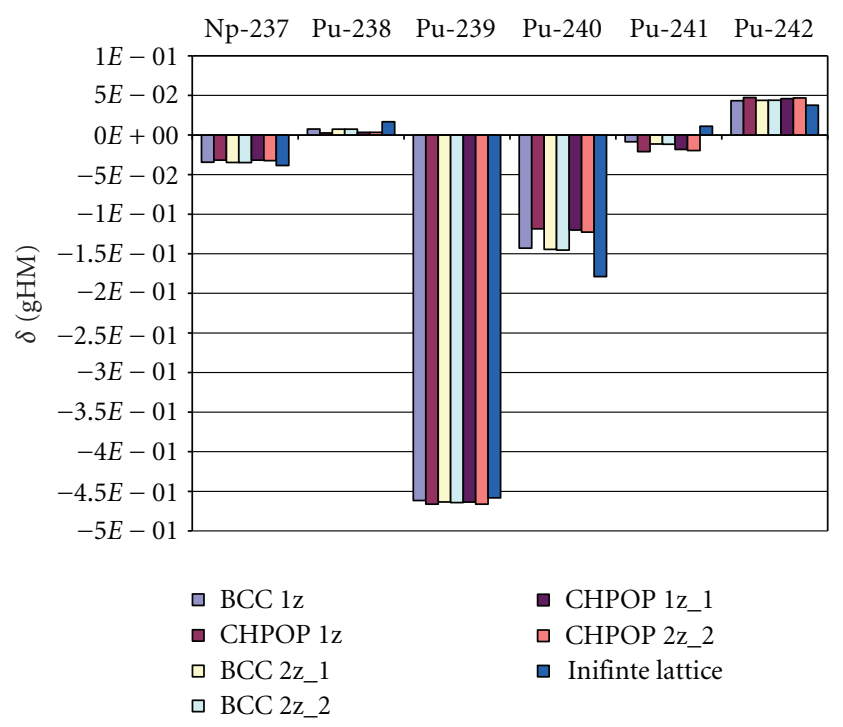

Figure 5: Production (grams) of Pu nuclides per initial HM mass in the different PBMR core models (after 1063 EFPD).

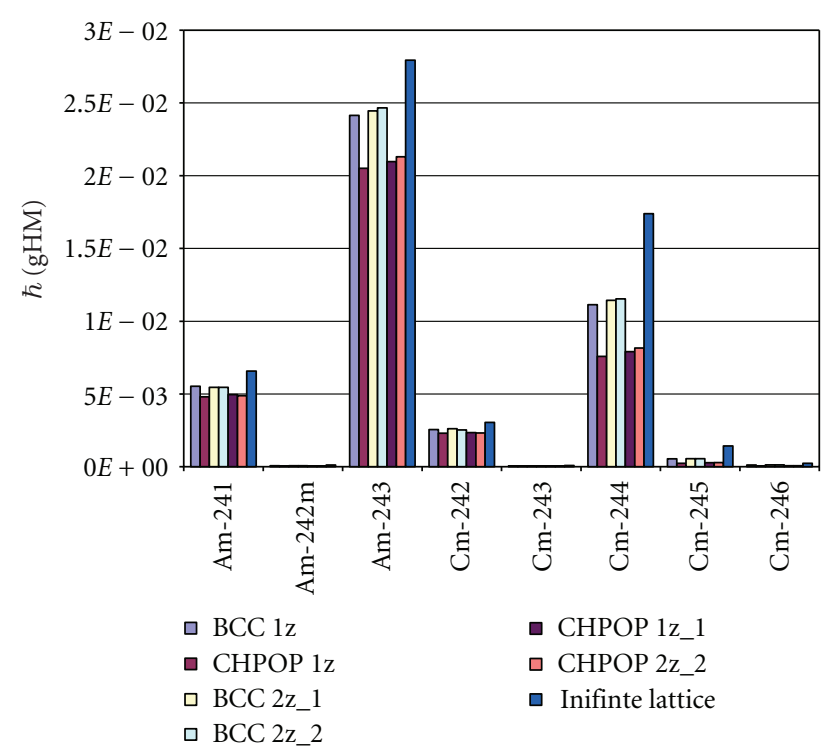

Figure 6: Production (grams) of Am and Cm nuclides per initial HM mass in the different PBMR core models (after 1063 EFPD).

Many of the results found in past work[1-7] are again confirmed: PBMR is a strong Pu and Np burner, but Am and $\mathrm{Cm}$ inventories increase substantially.

The isotopic $\mathrm{Np}$ and $\mathrm{Pu}$ vector in Table 4 constitutes the $\mathrm{Pu}+\mathrm{Np}$ vector for the GCFR fuel, which is shown in Table 5.

The length of each irradiation cycle has been set in order to reach a 10\% FIMA burnup. The cooling time between a cycle and the following has not been taken into account for the sake of simplicity. At the end of each considered cycle, the core is still critical. Then, if the fuel were still able to sustain irradiation from the damage point of view, its length could be further increased. The results obtained are illustrated in the Figures 7, 8, and 9. Please note that masses 
TABLE 4: PBMR HM composition after 713 EFPD.

\begin{tabular}{cccccccccccc}
\hline & $\mathrm{Np}^{237}$ & $\mathrm{Pu}^{238}$ & $\mathrm{Pu}^{239}$ & $\mathrm{Pu}^{240}$ & $\mathrm{Pu}^{241}$ & $\mathrm{Pu}^{242}$ & $\mathrm{Am}^{241}$ & $\mathrm{Am}^{243}$ & $\mathrm{Cm}^{242}$ & $\mathrm{Cm}^{244}$ & $\mathrm{Others}^{24}$ \\
\hline Mass fraction (\%) & 7.97 & 5.48 & 25.97 & 29.31 & 16.54 & 11.18 & 0.91 & 1.85 & 0.19 & 0.41 & 0.19 \\
\hline
\end{tabular}

TABle 5: GCFR initial HM composition ( $82 \%$ at DU + 18\% Pu+Np from PBMR; please see Table 4).

\begin{tabular}{ccccccccc}
\hline & $\mathrm{U}^{235}$ & $\mathrm{U}^{238}$ & $\mathrm{~Np}^{237}$ & $\mathrm{Pu}^{238}$ & $\mathrm{Pu}^{239}$ & $\mathrm{Pu}^{240}$ & $\mathrm{Pu}^{241}$ & $\mathrm{Pu}^{242}$ \\
\hline Mass fraction (\%) & 0.20 & 81.71 & 1.50 & 1.03 & 4.88 & 5.50 & 3.11 & 2.11 \\
\hline
\end{tabular}

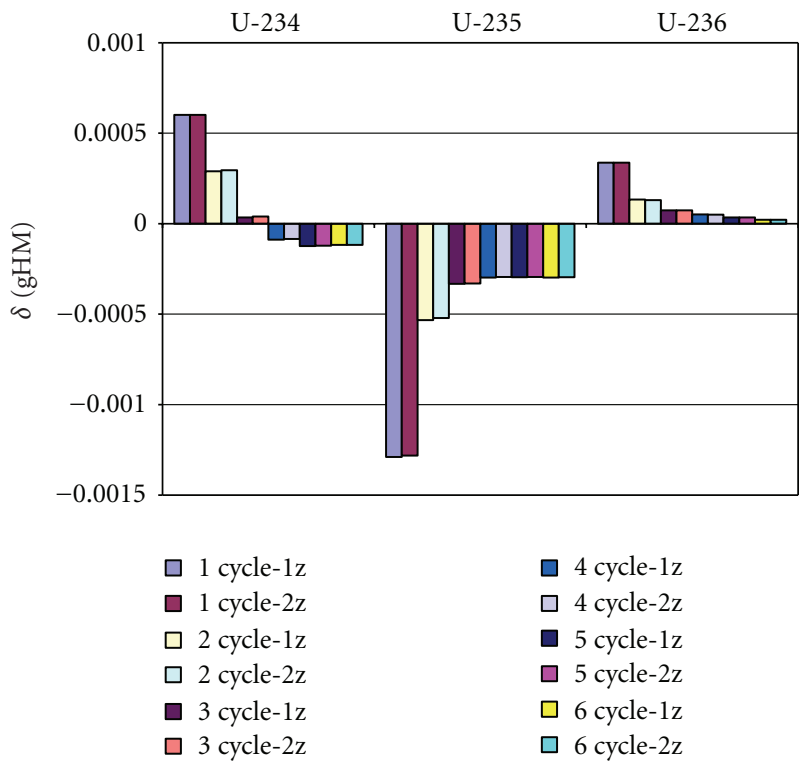

Figure 7: Production/destruction of some U nuclides per initial HM mass in the different GCFR core models, for each recycle.

here reported are referred to the average content of the whole core, regardless of the number of the axial zone number (1 or 2). It is interesting to note that, similarly to the PBMR models, having 1 or 2 axial zones does not influence strongly the prediction of the isotopic composition.

As an additional result, it has been found that $\mathrm{k}_{\text {eff }}$ at BOC increases with multiple recycling [1].

As observed for the PBMR core model, using 1-zone instead of 2-zone model does not cause significant changes in the final composition of SNF (Figures 7, 8, and 9). Conversely, the model is very important when dynamic parameters are under investigation. However, much more detailed investigations are needed to evaluate dynamic parameters of the core and their trends.

We can also observe that the condition of "zero breeding gain," envisaged for GCFR, is progressively obtained by multiple recycling (see $\mathrm{Pu}^{239}$ and $\mathrm{Pu}^{241}$ in Figure 8).

The strategy of the GCFR "E" fuel cycle shows the following advantages.

(i) First of all, removing Am and $\mathrm{Cm}$ from the spent fuel allows in principle the possibility to recycle $\mathrm{U}, \mathrm{Pu}$, and $\mathrm{Np}$ a large number of times, since the neutronic dose and the heatload of the SNF are kept constant. Then, a virtually full exploitation of $\mathrm{U}$ resources is obtained.

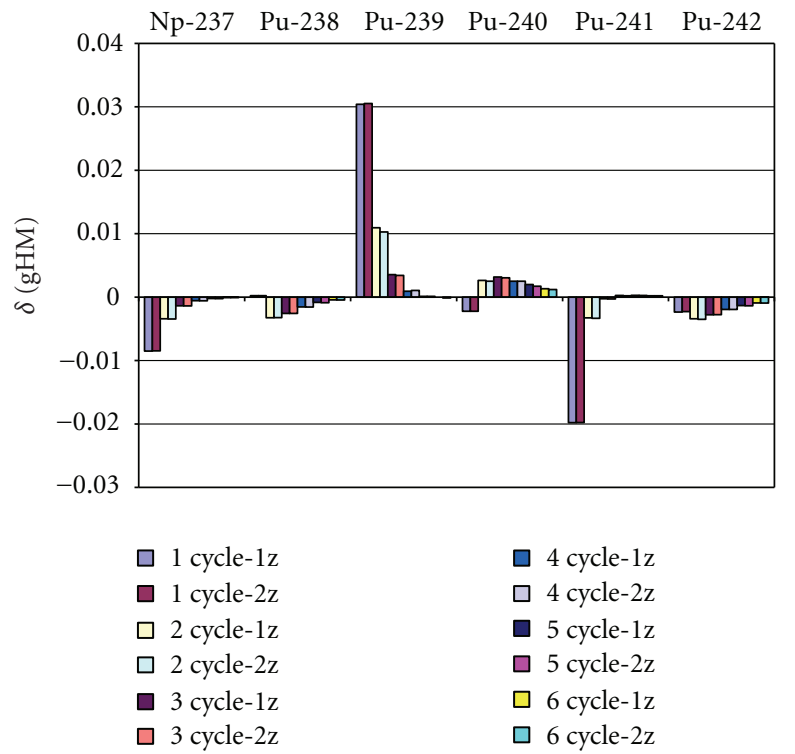

Figure 8: Production/destruction of some $\mathrm{Np}$ and $\mathrm{Pu}$ nuclides per initial HM mass in the different GCFR core models, for each recycle.

(ii) Pernicious $\mathrm{Pu}$ isotopes are monotonously decreasing from cycle to cycle.

(iii) $\mathrm{Am}$ and $\mathrm{Cm}$ increase from $\mathrm{BOC}$ to EOC even slower from cycle to cycle.

(iv) The isotopic evolution of the fuel from cycle to cycle is good from the safety point of view (after the relatively small drop between first and second cycle, $\mathrm{U}$ content increases.)

(v) Waste produced per unit energy is extremely small (please see next paragraph).

Nevertheless, there are some drawbacks as well, include the follwing.

(i) Times to reach equilibrium composition are very long (after about 60 years equilibrium has still to be reached.)

(ii) The reactivity at $\mathrm{BOC}$ tends to increases from cycle to cycle. That may be a problem from the point of view of the control reactivity device design.

(iii) The reduction of the long term radiotoxicity of the final waste (i.e., FPs, Am, and $\mathrm{Cm}$ ) might be obtained by designing dedicated assemblies. 


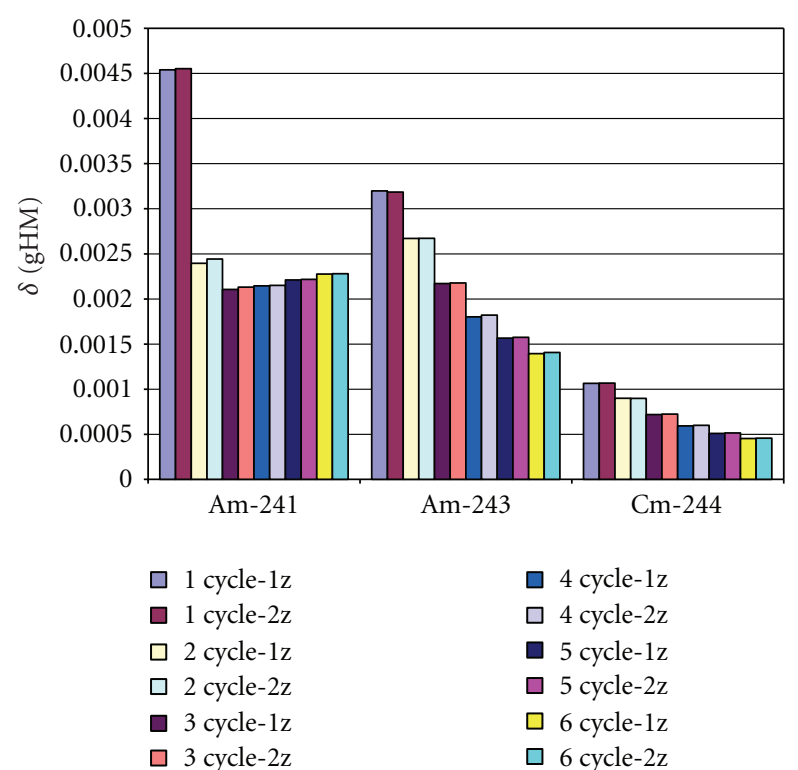

Figure 9: Production/destruction of some Am and Cm nuclides per initial HM mass in the different GCFR core models, for each recycle.

\section{Radiotoxicity and Heatload of the Final Waste}

First of all, calculating of the Level Of Mine (LOM) is useful to assess the impact of the integrated cycle strategy regarding the radiotoxicity of the final waste.

LOM calculation procedure has been extensively explained in [4].

In the considered case, we have to take into account that the following hold.

(i) Every year about $250 \mathrm{~kg}$ of $\mathrm{Pu}+\mathrm{Np}$ are discharged by the LWR considered as a reference.

(ii) Considering 712.5 EFPD the discharge burnup for PBMR pebbles, this core requires about $155 \mathrm{~kg} /$ year of $\mathrm{Pu}+\mathrm{Np}$ from LWR. That means each PBMR needs 0.62 LWR supplying its annual fuel charge.

(iii) In order to feed the first GCFR core, containing 13.7 $\mathrm{t}$ of $\mathrm{Pu}+\mathrm{Np}$ from PBMR SNF (712.50 EFPD, i.e., 356 $\mathrm{GWd} / \mathrm{tHM}$ ), SNF from about 56 PBMRs is required.

(iv) The radiotoxicity of the natural $\mathrm{U}$ is $20 \mathrm{mSv} / \mathrm{g}$.

(v) To obtain $1 \mathrm{~g}$ of $\mathrm{U}$ enriched to $3 / 4 \%, 10 \mathrm{~g}$ of natural $\mathrm{U}$ are required.

(vi) We will assume equal to zero the radiotoxicity of DU (in order to obtain the worst conditions).

The numerical ratio between LWR, HTR, and GCFR is not particularly favorable from the economical point of view. Indeed, yearly $1 \mathrm{PBMR}$ is able to burn the $\mathrm{Pu}+\mathrm{Np}$ inventory coming from 0.62 LWR. However, 1.3 PBMR, which can burn the whole $\mathrm{Np}+\mathrm{Pu}$ mass coming from $1 \mathrm{LWR}$, correspond to 800 MWth while 1 LWR corresponds to 3030 MWth. What is more, $56 \mathrm{PBMR}$ cores are capable for supplying the fuel mass to start a new GCFR core. Hence, it is clear that this is a very difficult matter and, in order to evaluate this

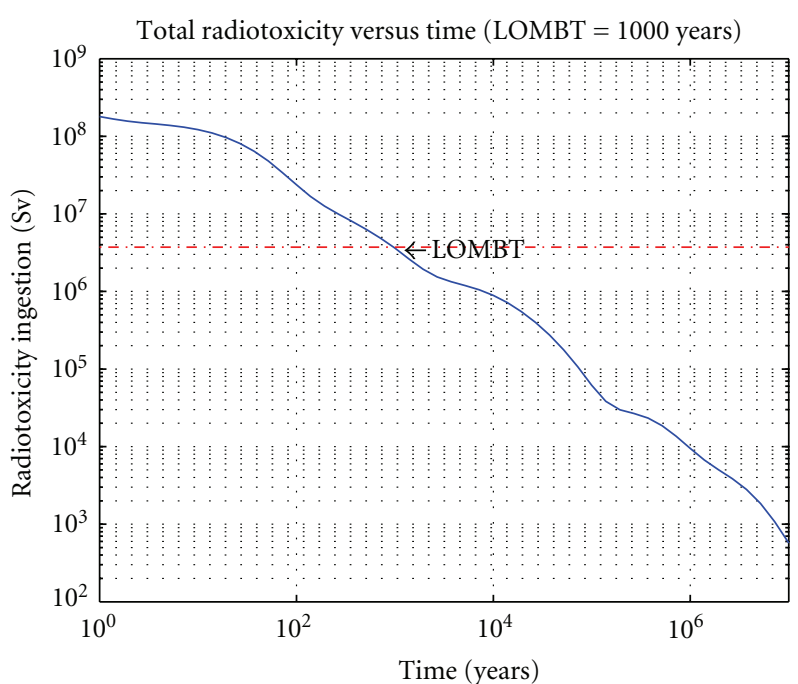

Figure 10: LOMBT of PBMR SNF (FPs, Am, and Cm).

aspect rigorously, we should perform a complete analysis of the scenario in which our cycle could be inserted [1].

Then, we are capable for calculating the LOM of the SNF of each reactor of our chain.

Since there are not any significant differences between 1-zone and 2-zore core models as far as the isotopic composition is concerned, we will show the results related to the 1-zone model for the sake of simplicity.

The results are summarized in the following Table 6 .

As know, the Level Of Mine Balancing Time (LOMBT) of LWR SNF, in the case of OTTO fuel cycle, is around 150000 years, since waste is composed of $\mathrm{U}, \mathrm{Pu}, \mathrm{MA}$, and FPs.

The integrated LWR-HTR-GCFR cycle causes a change of point of view, because $\mathrm{U}, \mathrm{Pu}$, and $\mathrm{Np}$ are fuel, and not waste anymore. Then, a strong reduction of the waste produced per unit energy ratio will occur (Table 7).

Results related to Radiotoxicity versus time as well as Heatload versus time are shown in the following Figures 10, $11,12,13,14,15,16,17,18,19,20,21,22,23,24,25,26,27$, $28,29,30$, and 31 .

It is interesting to highlight the following.

(i) First of all, the LOMBT is always lower than 20000 years. GCFR SNF reaches LOM after about 10000 except for the first cycle. PBMR SNF reaches LOM after 1000 years. Nevertheless, we have to remember that this low values are obtained thanks to recycling both $\mathrm{Pu}$ and $\mathrm{Np}$. If that was not true, the LOMBT would increase by an order of magnitude (e.g., cf. Figure 10, and 11).

(ii) The LOMBT of GCFR SNF decreases monotonously with multiple recycling. That is due to the progressive decrease of MA content of SNF.

(iii) It is interesting to note that the long-term radiotoxicity of GCFR SNF is substantially due to Am instead of Cm's daughters (this is different from what found in some past studies focusing on homogeneous multiple recycling in GCFR; please see [1-6]). This is in 
TABLE 6: LOM for SNF of the considered reactors.

\begin{tabular}{lcccc}
\hline & LWR & PBMR & GCFR $^{*}$ & Whole cycle \\
\hline LOM $[\mathrm{Sv}]$ & $6 \times 10^{6}$ & $3.72 \times 10^{6}$ & $2.10 \times 10^{8}$ & $2.10 \times 10^{8}$ \\
\hline
\end{tabular}

* Actually this value should be increased by the radiotoxicity of DU added to replace Am, Cm, and FPs of the GCFR SNF. However, no significant changes of results will happen, since the radiotoxicity of DU is lower than that of $\mathrm{U}_{\text {nat }}$.

TABLE 7: Waste per unit energy: comparison (chain composed of 1 GCFR "E”, 1.3 PBMR-400, 0.806 LWR).

\begin{tabular}{lcccc}
\hline & LWR 1000 & PBMR-400 & GCFR “E” & Integrated cycle \\
\hline FP [g/year] & $9.67 \times 10^{5}$ & $2.34 \times 10^{4}$ & $1.33 \times 10^{5}$ & $1.12 \times 10^{6}$ \\
Am [g/year] & $1.19 \times 10^{4}$ & $9.93 \times 10^{3}$ & $4.48 \times 10^{4}$ & $6.66 \times 10^{4}$ \\
Cm [g/year] & $9.23 \times 10^{2}$ & $2.34 \times 10^{3}$ & $8.37 \times 10^{3}$ & $1.16 \times 10^{4}$ \\
Thermal Energy [TWh/year] & $21 \times 39$ & 4.56 & 21.02 & 46.97 \\
Electric Energy [TWh/year] & 7.06 & 2.19 & 10.09 & 19.34 \\
Ratio waste/energy* [g/TWh & $1.13 \times 10^{6}$ & $7.83 \times 10^{3}$ & $8.87 \times 10^{3}$ & $2.56 \times 10^{4}$ \\
Ratio waste/energy* [g/TWh $_{\mathrm{e}}$ ] & $3.43 \times 10^{6}$ & $1.63 \times 10^{4}$ & $1.85 \times 10^{4}$ & $6.23 \times 10^{4}$ \\
\hline
\end{tabular}

${ }^{*}$ This results is obtained considering $30 \mathrm{t} /$ years of SNF for LWR (OTTO cicle).

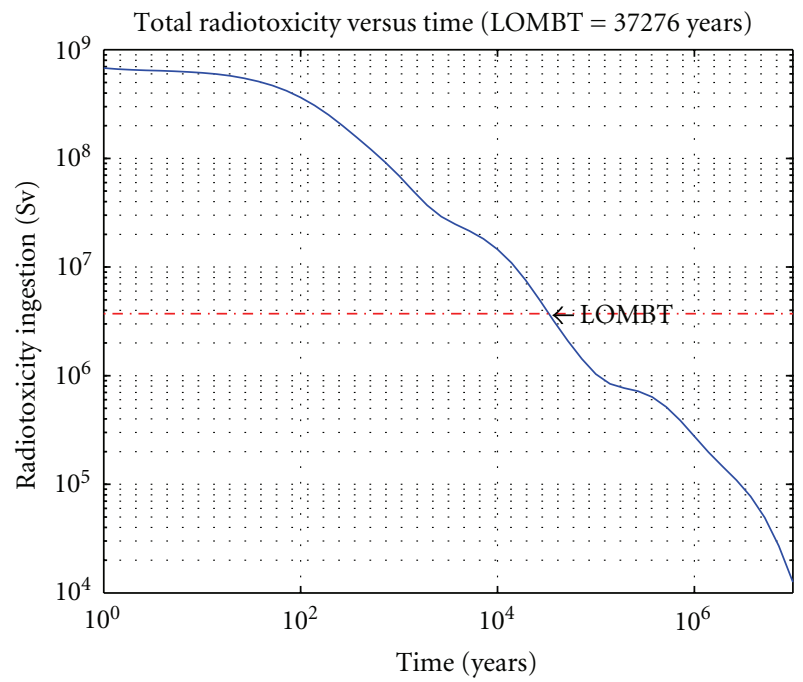

Figure 11: LOMBT of PBMR SNF (FPs, Pu, Am, and Cm).

principle an advantage of the strategy here chosen, because $\mathrm{Cm}$ decays in relatively small times while Am can be burnt in dedicated assemblies. Then, the results here achieved give us an important hint about a possible and feasible way to close the nuclear fuel cycle.

(iv) Heatload versus time does not show any remarkable behaviour.

\section{Conclusions}

The analysis performed in the framework of the EU project PUMA substantially confirms previous findings, but adding some remarkable developments.

Once again, as found out in previous researches, the integrated LWR-HTR-GCFR shows very good capabilities to achieve a sustainable nuclear fuel cycle.

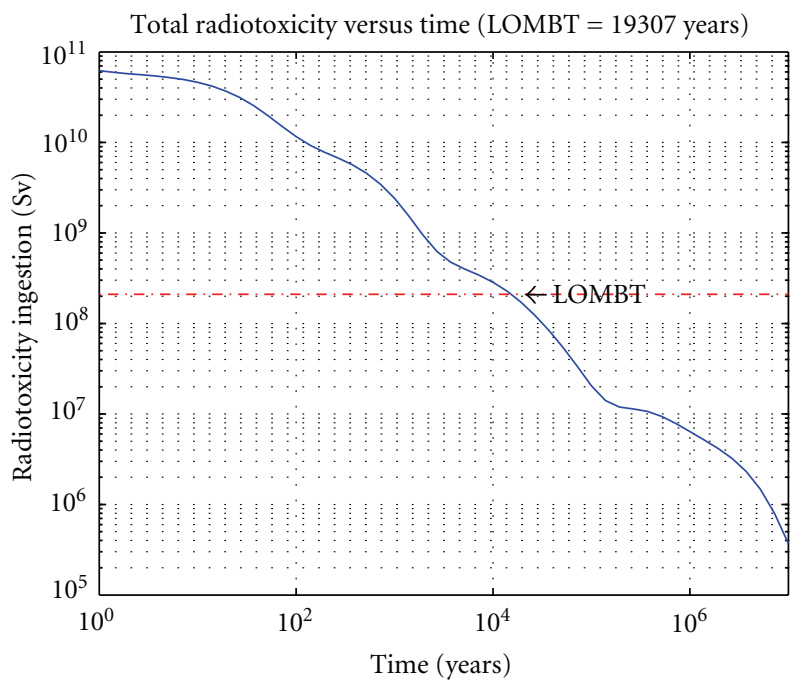

Figure 12: LOMBT of GCFR SNF end first cycle (FPs, Am, and $\mathrm{Cm})$.

As stated before, LWR-HTR-GCFR allows us the possibility to meet the following criteria.

(i) Excellent exploitation of $U$ resources intrinsically coupled with the strong reduction of the mass of the final waste (ratio waste/energy decreases by two orders of magnitude compared to OTTO).

(ii) Reduction of the radiotoxicity of the final waste to that of FPs and MAs (i.e., reduction of LOMBT by an order of magnitude compared to OTTO).

(iii) Strong reduction of $\mathrm{Pu}$ (and, if necessary, $\mathrm{Np}$ ) stockpiles thanks to HTR loaded with fertile-free fuel, in parallel with an important change of its isotopic composition, which becomes extremely proliferation resistant (fuel that contains high masses of strong heat- and neutron-emitters). 


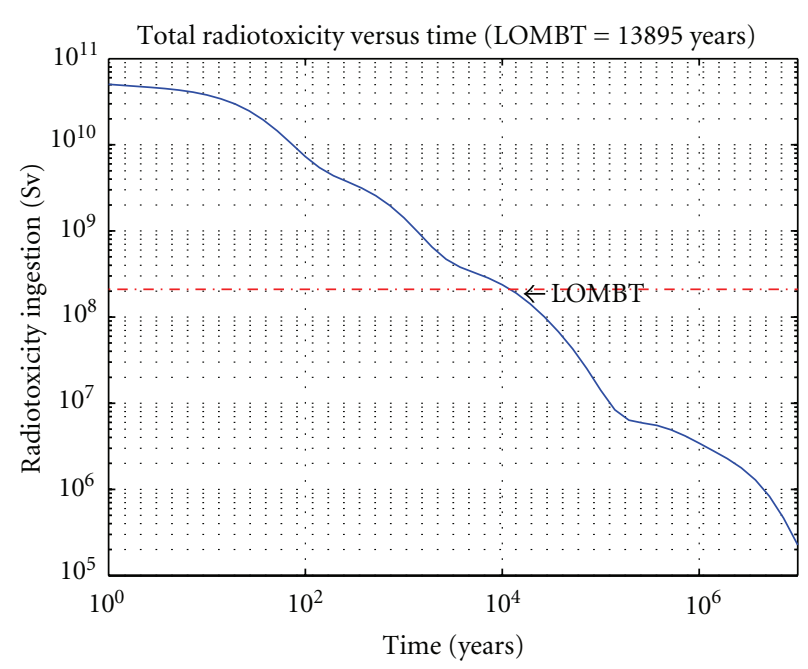

FIGURE 13: LOMBT of GCFR SNF end second cycle (FPs, Am, and $\mathrm{Cm})$.

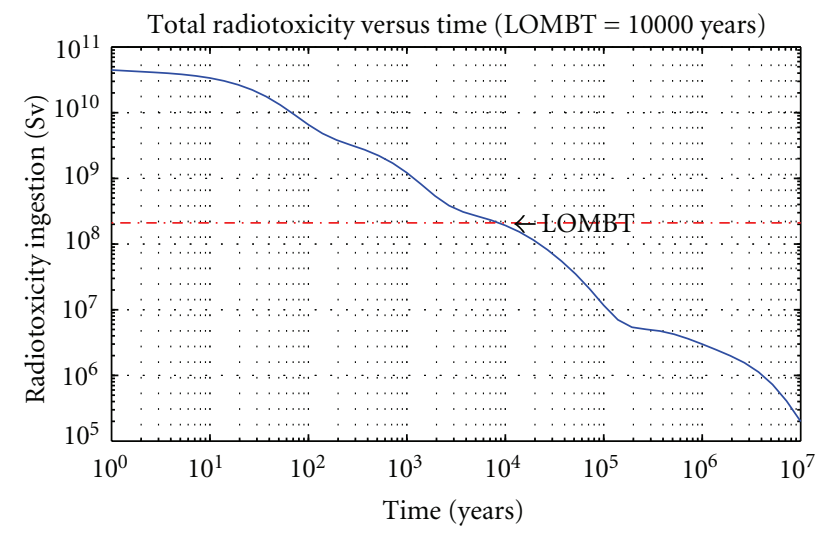

Figure 14: LOMBT of GCFR SNF end third cycle (FPs, Am, and $\mathrm{Cm})$.

(iv) Very long fuel cycles thanks to the very favourable neutron economy that is typical of He-cooled reactors

Additionally, the strategy here developed permits us some others improvements.

(i) Heterogeneous recycling of SNF (separating FPs, Am, and $\mathrm{Cm}$ from $\mathrm{U}, \mathrm{Np}$, and $\mathrm{Pu}$ ) in principle removes any technological limit to the possibility of recycling HMs many times. Indeed pernicious nuclides (these are, in any case, relatively small amounts.) like $\mathrm{Cm}$ isotopes are stored as a final waste or recycled in dedicated facilities.

(ii) Multiple recycling of GCFR SNF coupled to removing Am, Cm, and FPs shows the following important trends.

(a) Am and Cm amounts increase even slower from cycle to cycle.

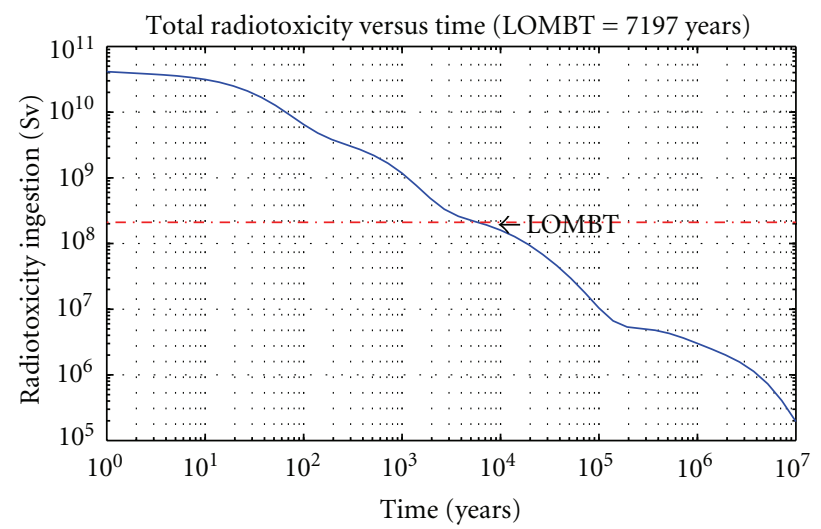

Figure 15: LOMBT of GCFR SNF end fourth cycle (FPs, Am, and $\mathrm{Cm})$.

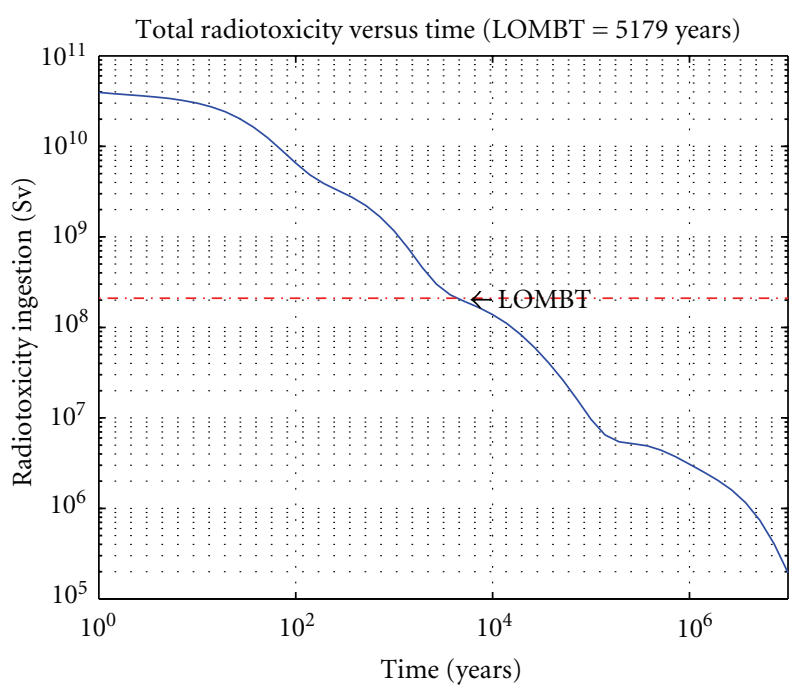

Figure 16: LOMBT of GCFR SNF end fifth cycle (FPs, Am, and $\mathrm{Cm})$.

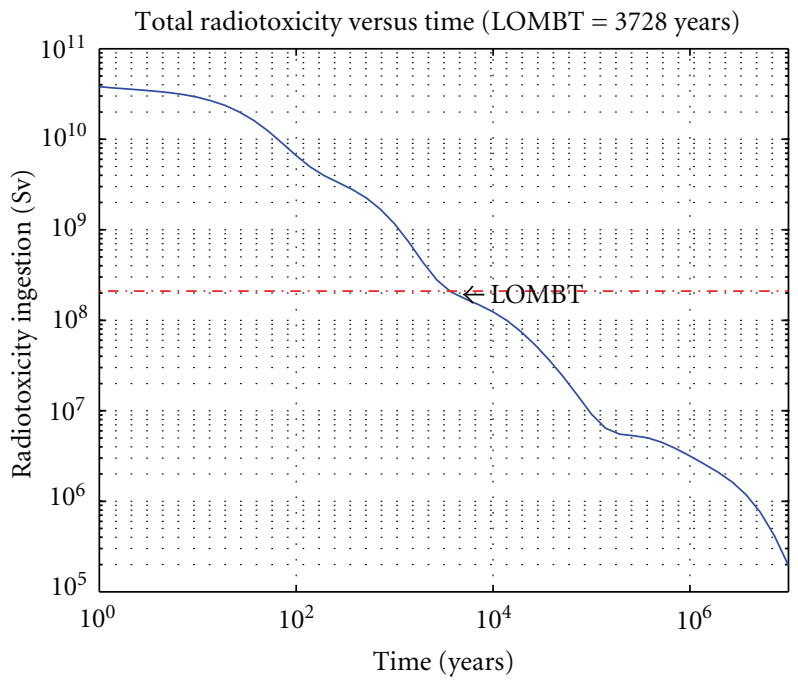

Figure 17: LOMBT of GCFR SNF end sixth cycle (FPs, Am, and $\mathrm{Cm})$. 


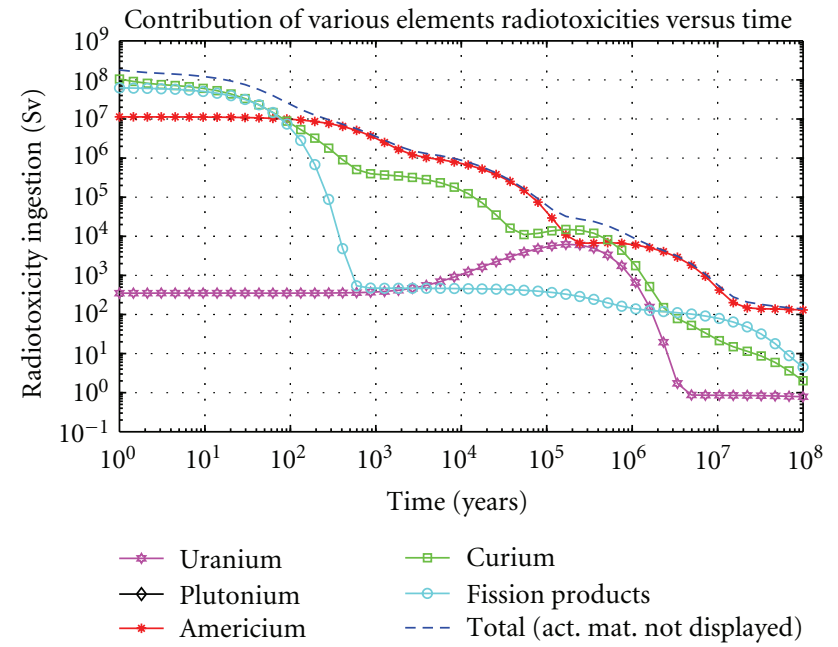

FIgure 18: Contributions to radiotoxicity versus time-PBMR SNF.

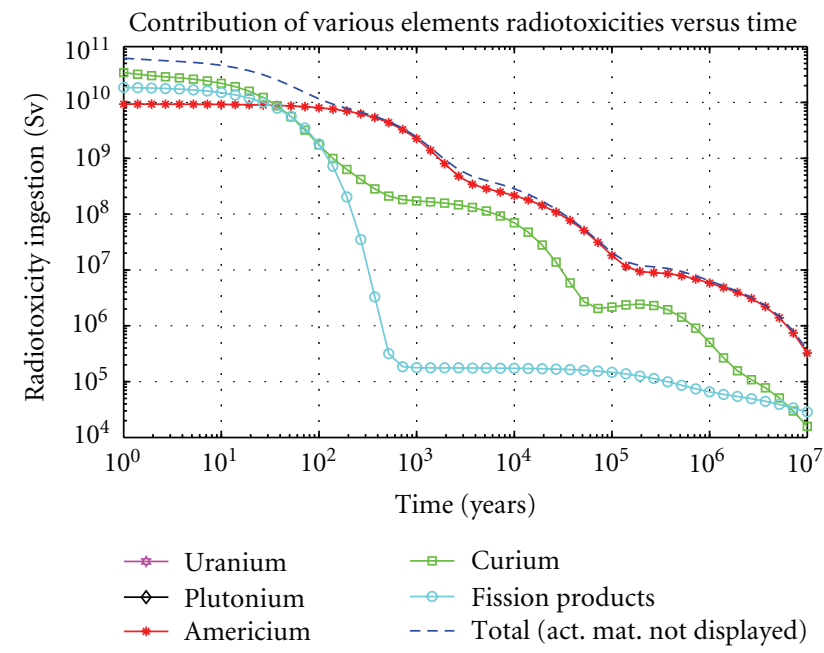

FIGURE 19: Contributions to radiotoxicity versus time-GCFR SNF end first cycle.

(b) As a consequence, the LOMBT of GCFR SNF (Am, Cm, and FPs) decreases from cycle to cycle.

(c) $\mathrm{Pu}$ isotopic composition is good enough to sustain very long irradiation cycles (more than 9 years in principle), but it is not suitable for military uses (high content of $\mathrm{Pu}^{240}$ ).

(d) Np is always burnt by both HTR and GCFR.

(e) $\mathrm{Pu}^{238}$, which is a strong alpha- and neutronemitter and then which could be pernicious for reprocessing, decreases during multiple recycling.

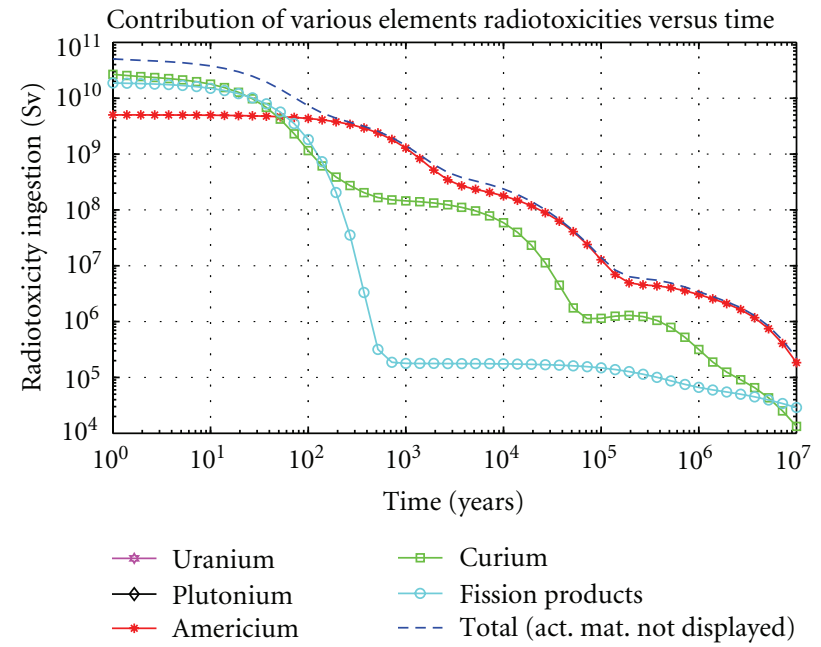

FIGURE 20: Contributions to radiotoxicity versus time-GCFR SNF end second cycle.

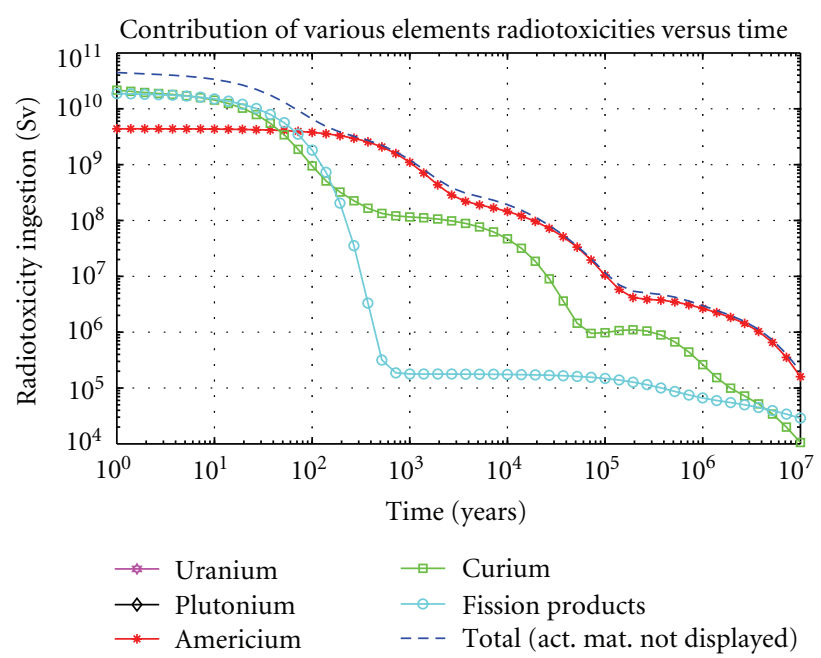

FIGURE 21: Contributions to radiotoxicity versus time-GCFR SNF end third cycle.

(iii) Radiotoxicity of GCFR SNF, after less than 100 years, is essentially due to Am nuclides instead of Cm ones: that indicates designing of a dedicated assembly to burn Am, along with an opportune cooling time of SNF, as a straightforward way to close the cycle effectively.

(iv) The excellent GCFR neutron economy and its huge DU inventory permits us the possibility to insert some dedicated assemblies to burn Am and $\mathrm{Cm}$ without significant consequences concerning core safety.

What is more, the analysis here performed gives us some clues regarding $\mathrm{He}$-cooled reactor core modelling as well. Particularly, we found that the following hold. 


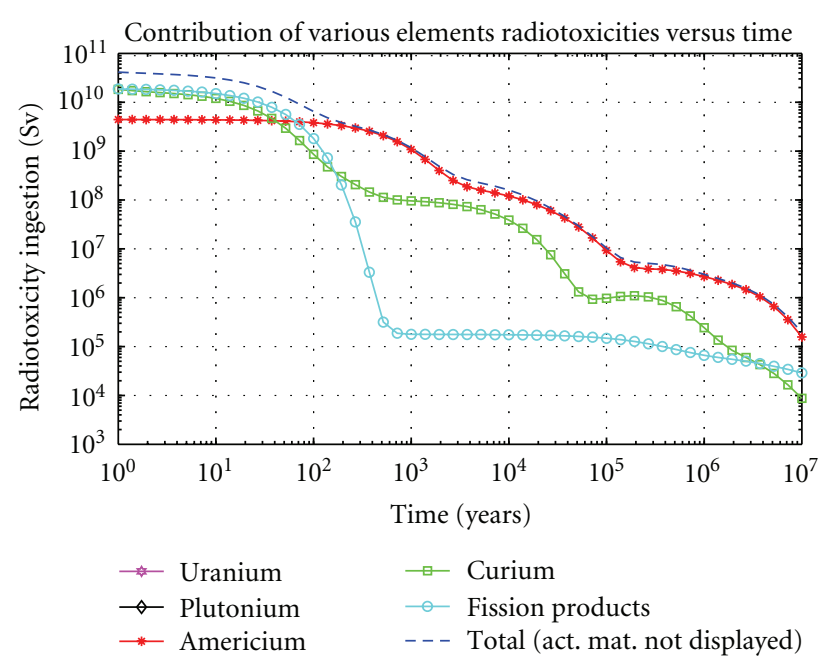

FIGURE 22: Contributions to radiotoxicity versus time-GCFR SNF end fourth cycle.

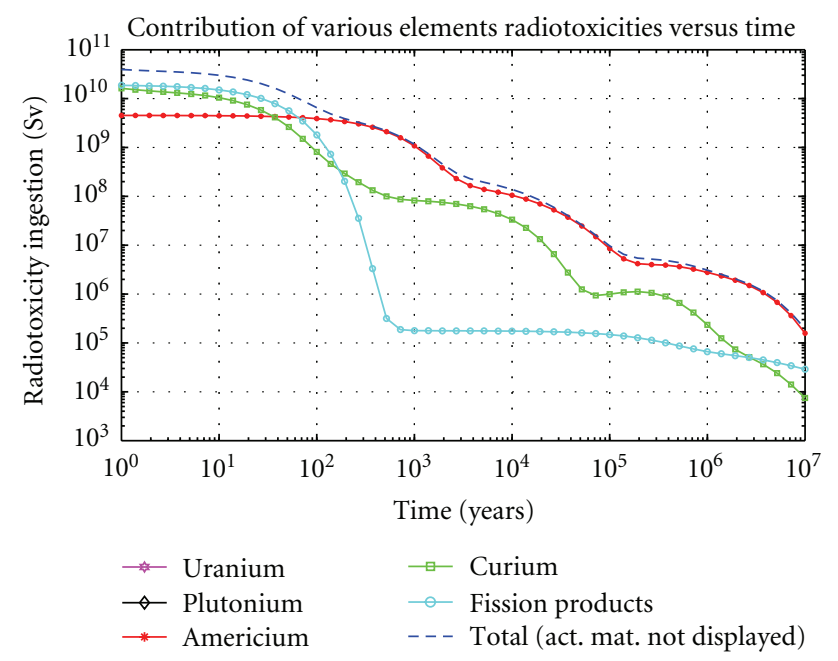

FIGURE 23: Contributions to radiotoxicity versus time-GCFR SNF end fifth cycle.

(i) As far as PBMR modelling is concerned, burnup calculations give results in good agreement with each other regardless the kind of (simplified) model chosen to describe the core itself [14]. Then, also due to the characteristics of the simulated reactor and taken into account the commonly used modelization approach (infinite lattice of pebbles with white conditions on the boundary), the use of quite rough models can be a good approximation, at least if we are only interested in the final isotopic composition. What is more, current MCNP based burnup codes still do not allow us by far to simulate such a complex core like the pebble-bed HTRs one, then the use of approximated models is necessary, at least

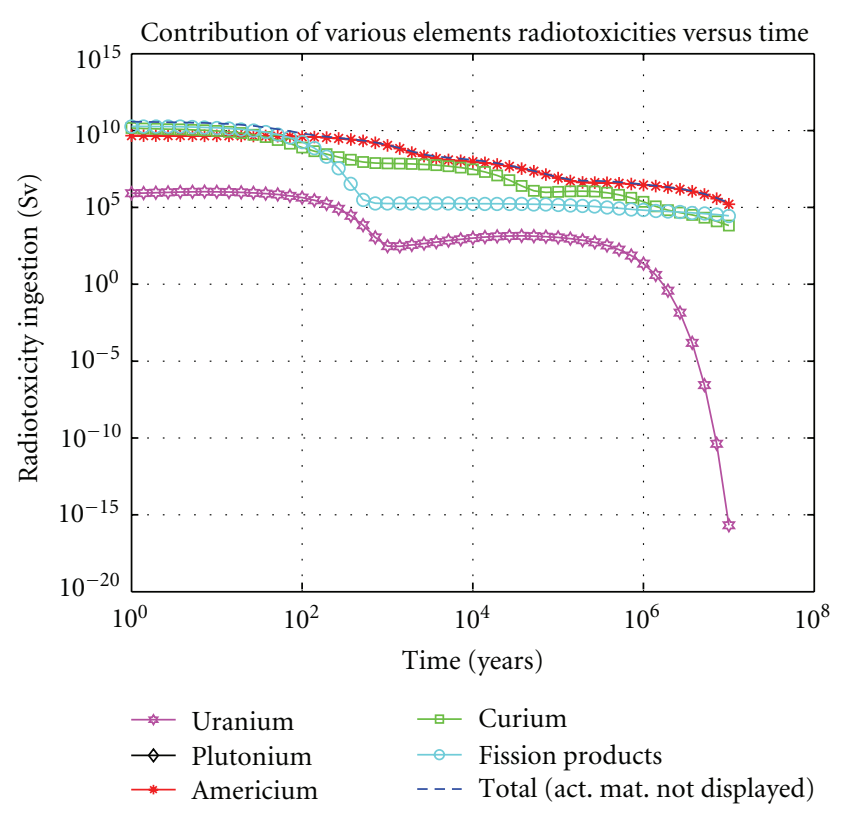

FIGURE 24: Contributions to radiotoxicity versus time-GCFR SNF end sixth cycle.

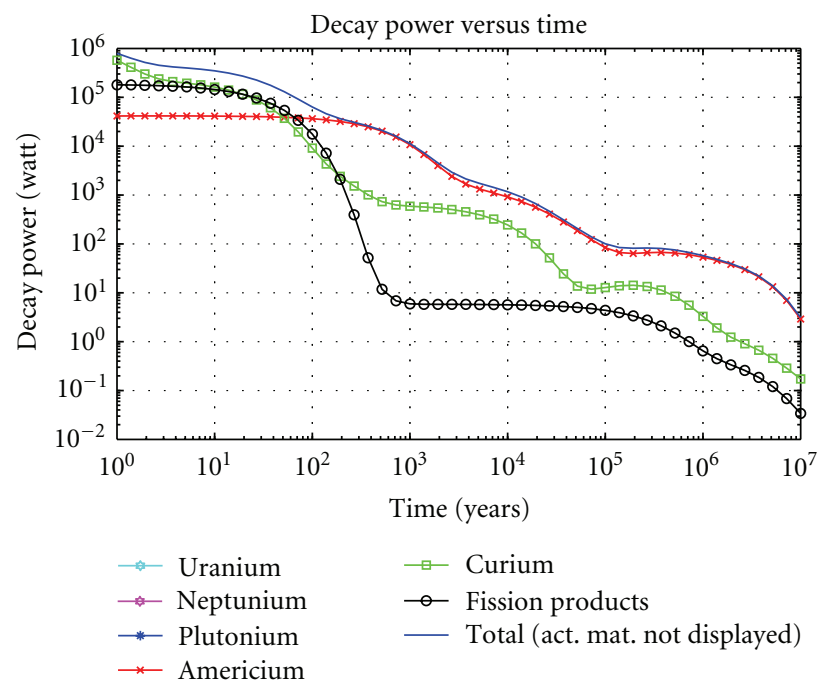

FIGURE 25: Contributions to heatload versus time-PBMR SNF.

at the moment. Conversely, dynamic parameters are very badly estimated by approximated models, thus we cannot rely on results supplied by this kind of calculation (some further explanations on this matter can be found in $[1,14])$.

(ii) Both PBMR and GCFR isotopic inventory versus burnup seems to be only slightly influenced by the axial temperature profile that can be described with Monteburns2.0 (i.e., varying only the temperature of not-burnable materials), so that it is not worth 


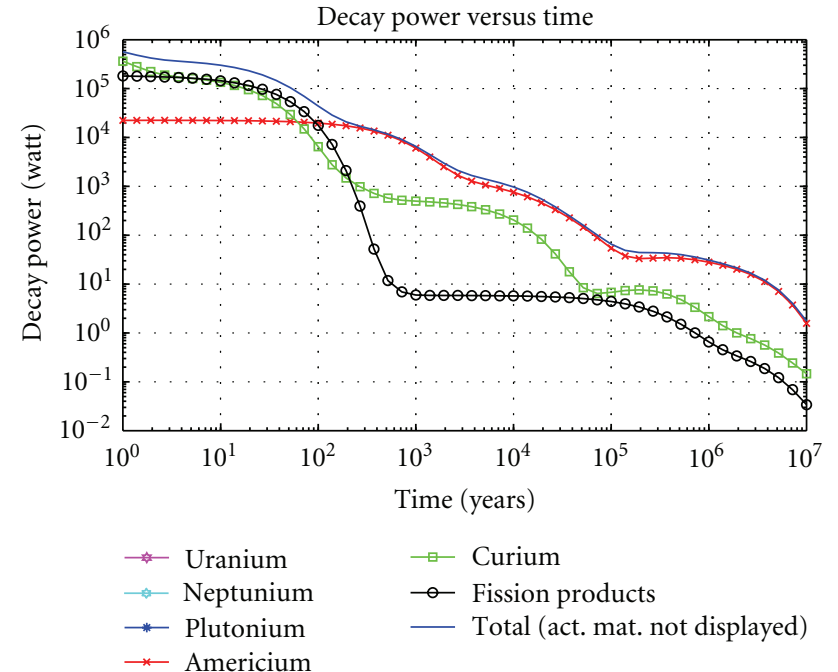

Figure 26: Contributions to heatload versus time-GCFR SNF end first cycle.

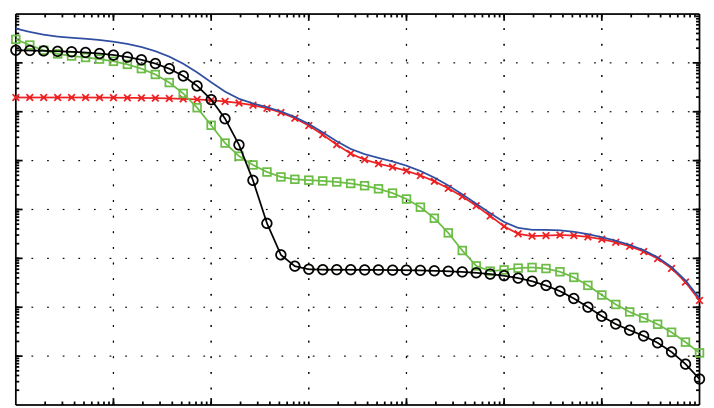

FIGURE 27: Contributions to heatload versus time-GCFR SNF end second cycle.

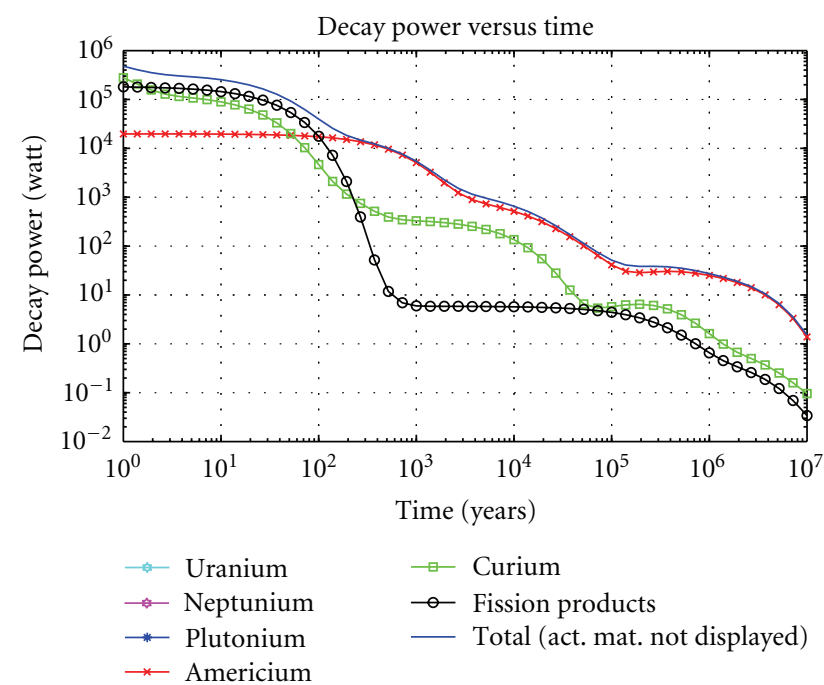

FIGURE 28: Contributions to heatload versus time-GCFR SNF end third cycle.

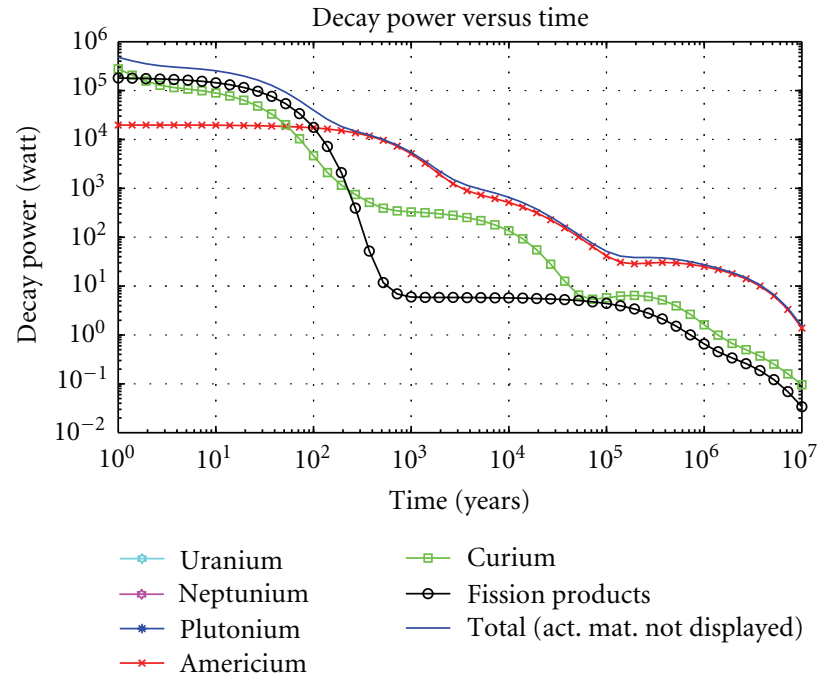

Figure 29: Contributions to heatload versus time-GCFR SNF end fourth cycle.

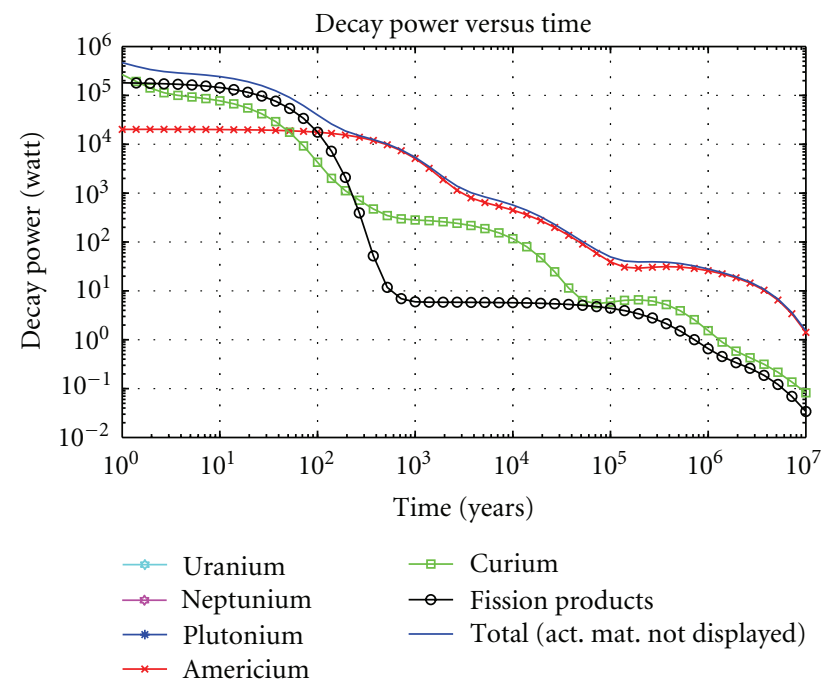

Figure 30: Contributions to heatload versus time-GCFR SNF end fifth cycle.

increasing calculation time because of a 2-zone model. Thus, we can adopt 1-zone models to simulate irradiation histories of these cores, having an higher calculation speed as a benefit.

(iii) On the other hand, GCFR reactivity parameters are also strongly influenced by axial temperature profile, so that we cannot rely on the results found with our approximated models.

As a future work, to close this cycle effectively, designing a dedicated assembly for Am and Cm burning is requested. Of course, a fuelling scheme for the GCFR core is necessary as well. 


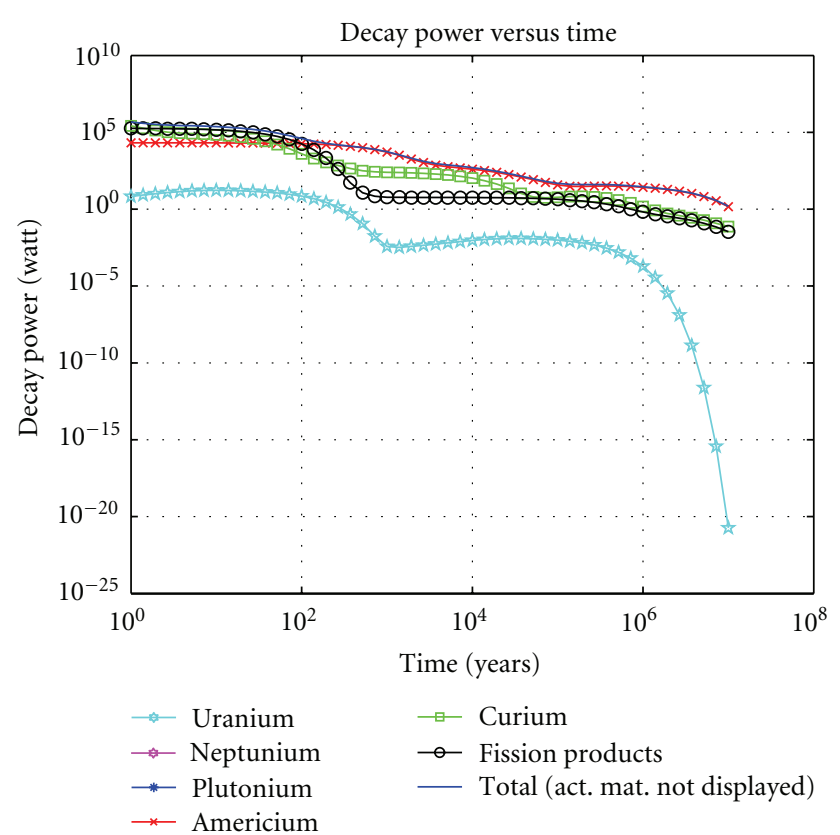

FIGURE 31: Contributions to heatload versus time-GCFR SNF end sixth cycle.

Finally the obtained results should be very useful if inserted in a more complete scenario analysis (see also [15]).

However, the obtained results seems to be very promising as far as finding this final solution is concerned.

\section{Acknowledgments}

The work presented in this paper was partly funded by the European Union Sixth Framework Program, under contracts PuMA, GCFR, and RAPHAEL. First of all we would like to thank Dr. Somers of ITU, Dr. Mitchell of AMECNNC, Dr. Kuijper and Dr. van Heek both of NRG, and Prof. Kloosterman of TUD, Dr. von Lensa of FZJ for the collaboration. Finally, we want to thank Prof. Forasassi of DIMNP for his strong support and Dr. Bufalino of SORIT for his precious suggestions and help.

\section{References}

[1] E. Bomboni, N. Cerullo, and G. Lomonaco, "Assessment of LWR-HTR-GCFR integrated fuel cycle," EU PUMA Project, Work Package 1.2, Deliverable D127, February 2009.

[2] http://www.puma-project.eu/.

[3] E. Bomboni, N. Cerullo, G. Lomonaco, and V. Romanello, "Nuclear waste impact reduction using multiple fuel recycling strategies," in Proceedings of the 1st International Conference on Physics and Technology of Reactors Applications (PHYTRA '07), Marrakech, Morocco, March 2007.

[4] E. Bomboni, N. Cerullo, G. Lomonaco, and V. Romanello, "A critical review of the recent improvements in minimizing nuclear waste by innovative gas cooled reactors," Science and Technology of Nuclear Installations, vol. 2008, Article ID 265430, 18 pages, 2008.
[5] E. Bomboni, "New developments in actinides burning with symbiotic LWR-HTR-GCFR fuel cycles," in Proceedings of the International Youth Nuclear Congress, Interlaken, Switzerland, September 2008.

[6] E. Bomboni, N. Cerullo, and G. Lomonaco, "New developments in actinides burning with symbiotic LWR-HTR-GCFR fuel cycles: perspectives and challenges," in Proceedings of the 10th International Exchange Meeting on Partitioning and Transmutation (IEMPT'08), Mito, Japan, October 2008.

[7] http://www.gcfr.org/.

[8] J. F. Briefmeister, "MCNP ${ }^{T M}$ - a general Monte Carlo nparticle transport code," Tech. Rep. LA-CP-03-0245, version 5, Los Alamos National Laboratory.

[9] A. G. Croff, "A User's Manual for the ORIGEN2 Computer Code," ORNL/TM-7175, July 1980.

[10] D. L. Poston and H. R. Trellue, "User's Manual Version 2.0 for Monteburns 1.0," LA-UR-99-4999, September 1999.

[11] http://www.perl.com/.

[12] W. Haeck and B. Verboomen, "A validated $\mathrm{MCNP}(\mathrm{X})$ cross section library based on JEFF3.1," Open Report SCK-CENBLG-1034 Rev. 0, October 2006.

[13] T. R. England, W. B. Wilson, and M. G. Stamatelatos, "Users manual for EPRI-CINDER code and data," EPRI-NP-356, LANL, December 1976.

[14] E. Bomboni, N. Cerullo, and G. Lomonaco, "Simplified models for pebble-bed HTR core burn-up calculations with MONTEBURNS2.0," Annals of Nuclear Energy.

[15] B. Vezzoni, N. Cerullo, G. Forasassi, et al., "Preliminary evaluation of a nuclear scenario involving innovative gas cooled reactors," Science and Technology of Nuclear Installations. 

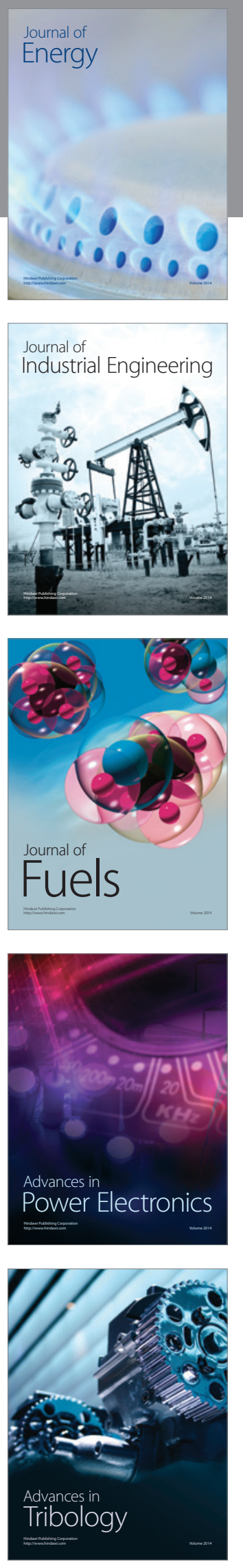
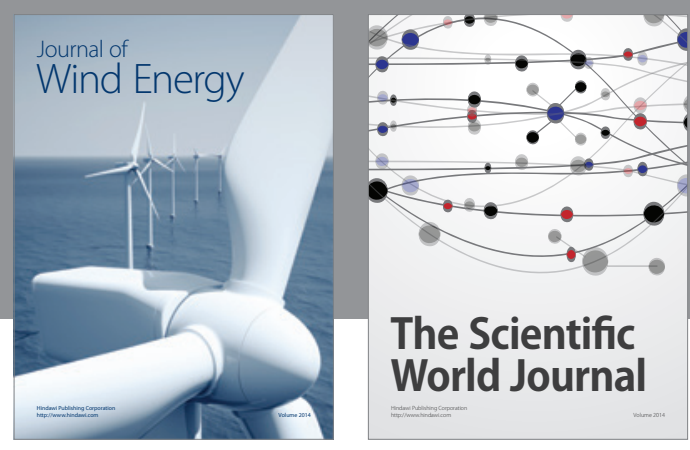

The Scientific World Journal

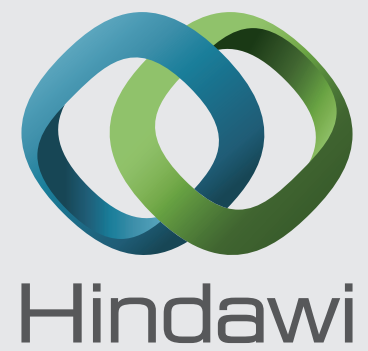

Submit your manuscripts at http://www.hindawi.com
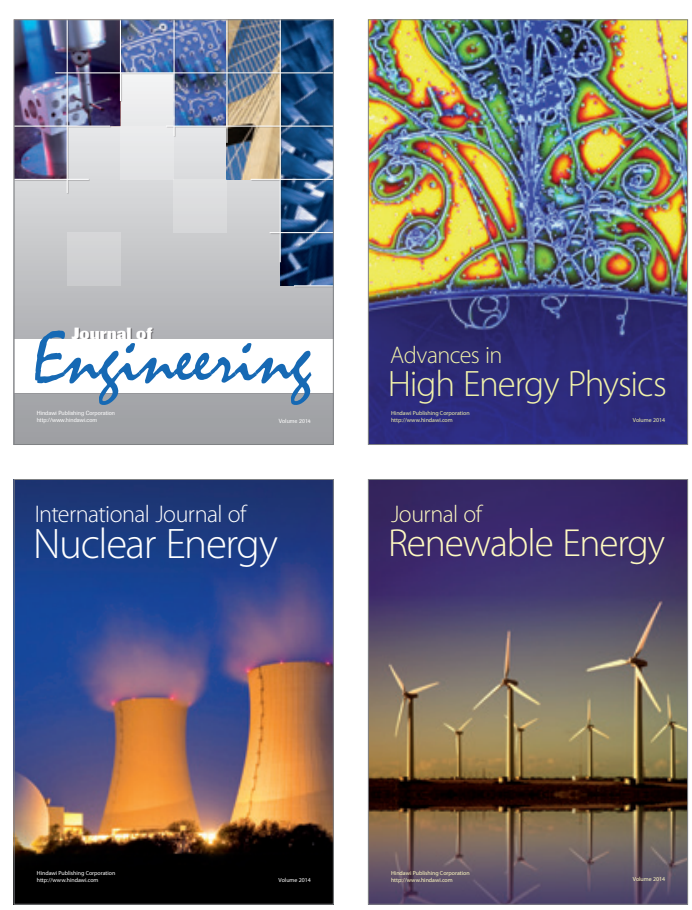

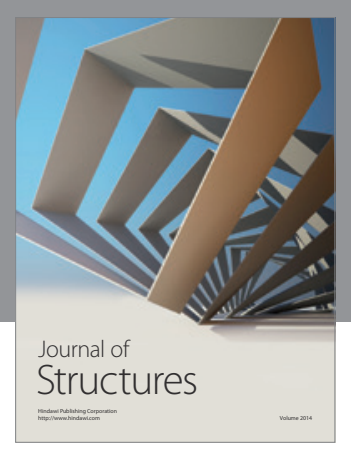

Rotating
Mechinery
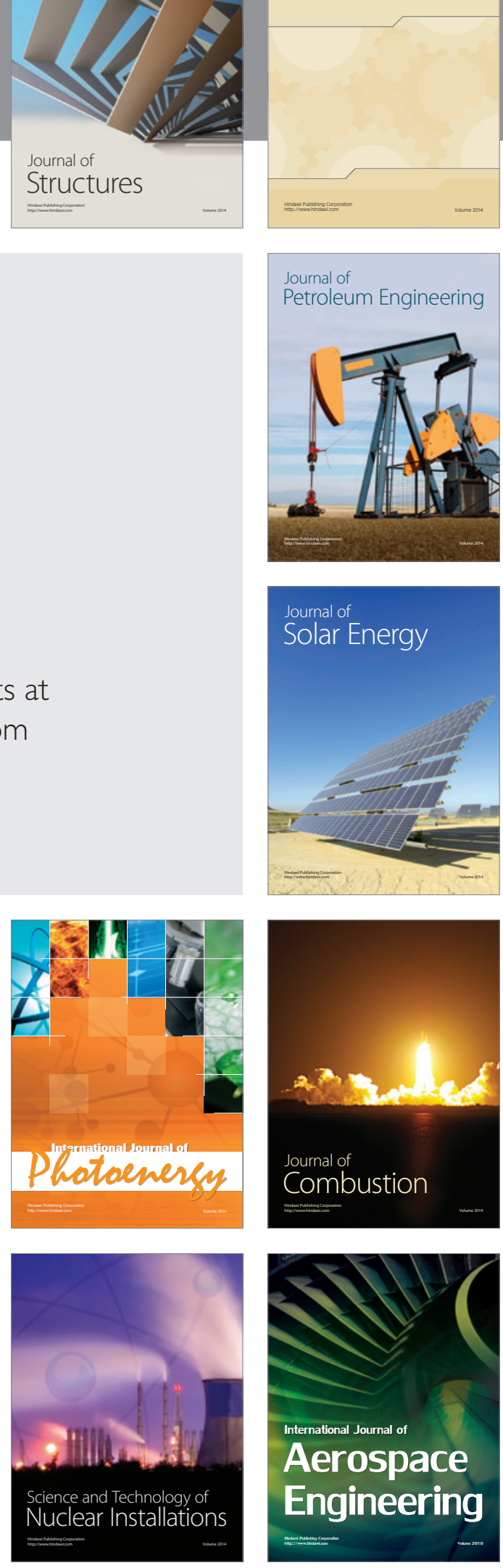